\title{
Estudo comparativo das ferramentas para mapeamento das atividades executadas pelos consumidores em processos de serviço
}

\author{
Gabriela Andre Jorge ${ }^{a *}$, Dario lkuo Miyake \\ aUniversidade de São Paulo, São Paulo, SP, Brasil \\ *gabrielajor@gmail.com
}

\begin{abstract}
Resumo
0 objetivo deste artigo é explorar o potencial de aplicação das ferramentas de mapeamento na construção de mapas de processo que evidenciem as atividades executadas pelos consumidores em processos de serviço. 0 artigo aborda as ferramentas SIPOC, Fluxograma, Blueprint, Process-Chain-Network, Mapa do Consumo, SERVPRO e Carta de Atividades, exemplificando sua aplicação na construção de mapas que oferecem diferentes visões processuais para um processo de compra via internet adotando a abordagem de decomposição hierárquica na análise do fluxo de atividades do consumidor. Estas ferramentas são analisadas quanto à capacidade de representar os diferentes aspectos do processo mapeado, considerando características como a forma de representação gráfica e o enfoque, abrangência e granularidade da visualização que oferecem. Finalmente, é apresentada uma avaliação comparativa da capacidade informativa destas ferramentas, procurando-se evidenciar o diferencial de cada uma.
\end{abstract}

Palavras-chave

Mapeamento de processos. Gestão de operações de serviços. Serviços. Consumidor.

\section{Introdução}

A aplicação das ferramentas de mapeamento é bastante difundida nos meios acadêmico e empresarial, quando motivada pela necessidade de criar mapas dos processos de organizações provedoras de produtos ou serviços para fins diversos como projeto, análise, benchmarking, padronização, informatização e treinamento. Por outro lado, a proposta de aplicação dessas ferramentas para a construção de mapas que retratem o fluxo das atividades desempenhadas pelos consumidores ainda é muito pouco explorada e difundida (Gummesson, 2008). Assim, enquanto as ferramentas de mapeamento têm sido muito aplicadas para a visualização dos fluxos dos processos de produção de bens ou serviços sob a perspectiva das empresas ou organizações, não se observa empenho semelhante por parte destas para visualizar os fluxos que impõem aos consumidores que necessitam acessar os bens ou serviços oferecidos. Isso sugere que no projeto e gestão de operações ainda prevalece entre os analistas o viés de considerar uma visão mais endógena que precisa ser revista, especialmente no contexto da produção de serviços em que o consumidor (ou usuário) percebe o processo de produção do serviço como parte do consumo do serviço e não apenas como resultado deste processo, contrastando com a perspectiva tradicional de consumo de produtos industrializados, ou seja, de resultados de um processo produtivo (Grönroos, 1998).

A proposição de considerar o ponto de vista do consumidor para fins de projeto, análise e controle operacional de processos de serviço, com base na premissa de que em processos de serviços os resultados do processo e sua avaliação são fortemente influenciados pela participação do consumidor e pelas percepções e expectativas deste, não é algo recente. Em áreas como administração de negócios de serviços, marketing de serviços e gestão da qualidade de serviços, ela foi introduzida por autores como lovelock \& Young (1979), Shostack (1984), Berry et al. (1985) e 
Parasuraman et al. (1985) há cerca de três décadas, tendo causado notável repercussão no âmbito acadêmico. Contudo, no contexto empresarial, permanece como uma prática obscura que não tem merecido a devida atenção. Portanto, é importante estimular e apoiar a disseminação da prática de mapear os processos desempenhados pelos consumidores em serviços.

Nas aplicações das técnicas de mapeamento na manufatura, em geral, os mapas construídos limitam-se a posicionar o consumidor no final do processo quando o bem lhe é entregue, ou no início do processo como demandante que impulsiona o processo produtivo. Para as empresas de manufatura que em geral têm pouca ou nenhuma interação direta com os consumidores finais de seus produtos, mapear as atividades desempenhadas por eles não é tão crucial para o seu negócio como para as empresas provedoras de serviços. No setor de serviços, o consumidor participa do processo de serviço interagindo com algum recurso da empresa provedora (e.g. funcionário, equipamento, site) e, muitas vezes, atua como coprodutor. A abordagem de delegar aos consumidores o papel de coprodutor que assume a execução de determinadas tarefas do processo no lugar de funcionários da empresa provedora do serviço é uma forma de racionalização bastante explorada (Mills \& Morris, 1986; Torres Junior \& Miyake, 2011).

A aplicação de técnicas de mapeamento para visualização das atividades do consumidor pode trazer contribuições aos gestores, principalmente, no planejamento, análise e controle de processos em que o consumidor tem de executar tarefas que influenciam o resultado final, pois o fato de assumir o papel de coprodutor de um serviço pode trazer certos benefícios ao consumidor, mas por outro lado implica impor-lhe um ônus maior em termos, por exemplo, de esforço físico e tempo a serem dedicados e recursos materiais, conhecimentos e habilidades que ele precisa dispor (Etgar, 2008). Assim sendo, o presente estudo tem como foco o potencial de aplicação das ferramentas de mapeamento na racionalização de processos de serviço que requerem maior participação do consumidor, incluindo a perspectiva deste agente.

0 mapeamento das atividades dos consumidores durante o processo de consumo de serviços é uma técnica que pode ser utilizada pelas organizações para melhorar seus processos produtivos e aumentar sua competitividade, proporcionando maior valor aos clientes. Conforme sugerem Ravald \& Grönross (1996, p. 12),

[...] se a empresa prover valor ao consumidor em termos de redução do sacrifício percebido por ele, reduzindo seus custos despendidos e melhorando o desempenho do consumidor, as chances de sucesso da empresa são evidentes.

lsso sugere que o desafio do gerenciamento das operações de serviço está em maximizar o benefício para o cliente, minimizar o custo financeiro e sacrifício para o cliente e minimizar o custo para a organização (Johnston \& Clark, 2002). Mais especificamente, o custo do serviço para o cliente pode estar atrelado a fatores como conveniência de deslocamento, esforço requerido, retrabalho e dificuldades para adquirir o serviço, tempo dedicado ao processo e recursos que precisa dispor para poder consumir o serviço. Destarte, entender com profundidade a forma como os consumidores vivenciam e avaliam o processo de serviço é um dos muitos desafios enfrentados pelas empresas que desenvolvem e oferecem serviços (Bitner et al., 2008). A partir de uma clara definição da proposta de valor que um dado serviço busca oferecer, o mapeamento e análise das atividades desempenhadas pelo consumidor tornam possível identificar desperdícios no processo - tarefas ou partes de tarefas que não agregam valor - e buscar sua eliminação ou redução.

Avanços nesse campo do conhecimento são necessários para facilitar o processo de construção de mapas que ajudem a capturar os diversos aspectos que caracterizam a experiência dos consumidores em processos de serviços e, assim, estimular maior disseminação das práticas de mapeamento que contemplem, mais especificamente, as formas de inserção e participação dos consumidores. A adoção de tal abordagem de mapeamento é fundamental para o levantamento de visões e dados que facilitem a identificação de oportunidades para aprimorar os processos de serviço.

Com base nessas premissas, este trabalho se propõe a explorar o potencial de aplicação das ferramentas de mapeamento, propostas pela literatura de planejamento e gestão de operações, na construção de mapas de processo que apoiem a descrição e análise do fluxo das atividades desempenhadas por consumidores em processos de serviço. Dentre as ferramentas identificadas na literatura, SIPOC, Fluxograma, Blueprint, Process-Chain-Network (PCN), Mapa do Consumo, SERVPRO e Carta de Atividades foram selecionadas para este estudo por terem propriedades que permitem representar o fluxo de atividades de agentes diversos, inclusive consumidores, em processos de serviços ou por já terem sido introduzidas com a noção de incluir a figura do consumidor no âmbito do processo a ser mapeado.

0 objetivo do trabalho é apresentar as diferentes visões que tais ferramentas oferecem e evidenciar o diferencial de cada uma por meio de uma análise 
comparativa do enfoque, abrangência e granularidade com que representam o processo mapeado. Além disso, com o intuito de orientar a prática da abordagem de mapear e visualizar o fluxo de atividades do consumidor, o trabalho também orienta a seleção da ferramenta com maior capacidade informativa dentre as sete pesquisadas, conforme o propósito do mapeamento. Para evidenciar seu caráter ilustrativo, o trabalho apoia-se na demonstração da aplicação das ferramentas consideradas na construção de mapas que oferecem diferentes visões processuais e analíticas para um processo de compra via internet.

\section{Método de pesquisa}

Inicialmente, para buscar um panorama atual da aplicação dos métodos de mapeamento de processos em geral, foi realizada uma pesquisa da literatura que trata deste tema. Esta pesquisa indicou que, apesar da ampla disseminação do uso de ferramentas de mapeamento que pode ser observada, a construção de mapas com o propósito de explicitar a participação do consumidor em processos de serviço é uma iniciativa ainda pouco discutida e praticada. Dessa forma, o presente estudo, do ponto de vista de seu objetivo, caracteriza-se como uma pesquisa exploratória (Gil, 1999), por se propor a abordar uma vertente de aplicação de ferramentas de mapeamento ainda pouco conhecida. Trata-se, portanto, de uma pesquisa em que os meios (ferramentas) examinados podem ser até convencionais, mas o fim considerado para sua aplicação aponta para uma prática ainda não disseminada, que carece de um arcabouço teórico-conceitual e de referências empíricas que sirvam para orientar sua sistematização e estimular sua adoção.

Dentre as diversas formas de mapeamento tratadas na literatura, foram identificadas sete ferramentas que podem ser usadas para visualizar a participação do consumidor em um processo de serviço, quais sejam, SIPOC, Fluxograma, Blueprint, PCN, Mapa do Consumo, SERVPRO e Carta de Atividades. Embora possam ser redundantes para registrar certos dados, cada uma dessas ferramentas revela características específicas que a torna mais apropriada para evidenciar determinados aspectos da forma de participação do consumidor no processo, o que, dependendo das circunstâncias, pode tornar a aplicação delas complementares. Assim, a seção 3 é dedicada a uma descrição destas ferramentas, com destaque de suas especificidades.

Para organizar a ilustração de como essas ferramentas podem ser aplicadas no mapeamento da experiência do consumidor, procurou-se considerar os cuidados metodológicos prescritos na literatura sobre mapeamento de processos. Diferentes procedimentos são sugeridos por autores que propõem que a construção de mapas de processo e sua aplicação na melhoria de processos sejam conduzidas de forma sistematizada (Tseng et al., 1999; Biazzo, 2000; Jacka \& Keller, 2009; George, 2003), mas de forma geral eles convergem para a adoção dos seguintes passos:

1. Definir o processo a ser mapeado e seus limites (onde começa e onde termina) e dividi-lo em algumas poucas atividades.

2. Capturar dados para descrição do processo e suas atividades.

3. Delinear um mapa de alto nível (high level) do processo numerando suas atividades e revisá-lo até torná-lo representativo da realidade observada (“As ls").

4. Gerar mapas com maior nivel de detalhe (low leve), decompondo as atividades a serem analisadas em tarefas mais específicas e adotando o procedimento de numeração progressiva para refletir a estrutura hierárquica.

5. Identificar oportunidades de melhoria no processo.

6. Desenhar um mapa que projete como o processo deveria ser ("To Be").

Dentre esses passos, os quatro primeiros estão relacionados com o propósito deste trabalho, que é o de explorar a aplicação das ferramentas de mapeamento para representar o processo executado pelos consumidores. Já os passos 5 e 6 destinam-se a um fim que extrapola o propósito do trabalho e não serão considerados.

Inicialmente, para definir o processo a ser mapeado (passo 1), dada a existência de uma oferta muito diversificada de serviços que os consumidores podem buscar, optou-se por focar um tipo de serviço em que a participação do consumidor no processo é mais significativa. Segundo Johnston \& Clark (2002), os processos de serviço podem ser classificados em quatro grandes categorias, quais sejam: projetos de serviço, parceria de serviços, fábrica de serviço e serviço do tipo "faça você mesmo", sendo o último o que apresenta maior grau de participação do consumidor. 0 escopo da pesquisa foi então limitado ao mapeamento da participação do consumidor em serviços do tipo "faça você mesmo", nos quais o consumidor atua preponderantemente como coprodutor, sendo o principal ou único responsável pela execução das atividades. Assim, selecionou-se o serviço de varejo eletrônico, que possibilita aos consumidores realizarem o processo de compra daquilo que necessita pela internet. Trata-se de um processo atrelado ao negócio de comércio eletrônico que, em nível mundial, cresceu a uma taxa composta média 
anual de 17\% entre 2007 e 2012, quando atingiu a cifra de US\$ 521 bilhões em vendas online, e que assim tem se tornado familiar a uma crescente parcela da população. No Brasil, por exemplo, 57\% dos cerca de 90 milhões de usuários de internet já fazem compras online (Ben-Shabat et al., 2013). Dessa forma, este serviço tem grande valor ilustrativo para servir como objeto a ser descrito e analisado na avaliação da aplicabilidade das ferramentas de mapeamento em estudo, dada a sua crescente difusão, por envolver tarefas, que independentemente daquilo que se pretende comprar, seguem uma lógica comum, e pela sua natureza de se apoiar num processo de serviço do tipo "faça você mesmo", em que o consumidor é encarregado de executar grande parte do processo.

Para delimitar o processo a ser mapeado, foram selecionados cinco sites brasileiros que operam como lojas de eletroeletrônicos ou livrarias que oferecem uma grande diversidade de bens de consumo além de livros em si, as quais se destacam como tipos de negócio posicionados entre aqueles com maior participação no varejo eletrônico (Ben-Shabat et al., 2013) e, pela navegação em suas páginas, foi verificada a sequência de atividades que o consumidor precisa executar para comprar um produto por meio destes.

Para a condução do passo 2, os pesquisadores identificaram preliminarmente os dados que seriam requeridos para a construção de mapas de processo com as ferramentas em estudo. Dada a motivação de procurar construir mapas que retratem a experiência do consumidor, foi considerada a necessidade de capturá-la de uma maneira que refletisse o contexto real vivenciado pelo consumidor durante a execução do processo de serviço objeto de estudo. Assim, os pesquisadores optaram pela adoção da abordagem de experimentar a realização deste serviço colocando-se na posição de clientes reais, ou seja, submetendo-se ao encargo de executar realmente a sequência de atividades que os sites considerados delegam ao consumidor e, concomitantemente, proceder a levantamentos observando diretamente a interação com o processo de serviço estudado para caracterizar sua participação.

Com os dados assim coletados, por imersão dos pesquisadores no ambiente real do processo focado, os mapas em alto nível (passo 3) foram delineados de uma forma geral logo após execução de experimentos iniciais. Já o desdobramento das atividades identificadas nestes em tarefas mais específicas (passo 4) demandou a definição das partes do processo a serem detalhadas e a realização de experimentos complementares para a análise destas partes, progressivamente, num nível de detalhe intermediário, e em seguida num nível mais profundo. As visões da experiência do consumidor assim capturadas em diferentes níveis foram diagramadas conforme as convenções preconizadas por cada uma das 7 ferramentas cuja aplicação se pretende ilustrar e são apresentadas na seção 4.

Algumas ferramentas requerem também a descrição de atividades do provedor que não puderam ser observadas nos experimentos. No entanto, como a construção de mapas de processo sob a perspectiva do provedor não constitui o foco deste trabalho, apenas a título de ilustração, o fluxo de tais atividades foi elaborado genericamente com base no conhecimento sobre a realização de transações do tipo Business-to-Consumer (B2C) entre sites de comércio eletrônico e consumidores, adquirido pelos pesquisadores por meio de pesquisas de campo.

Em seguida, na seção 5, considerando as diferentes perspectivas do processo de serviço do tipo "faça você mesmo" capturadas mediante aplicação das ferramentas de mapeamento focadas neste estudo, estas são analisadas para se avaliar comparativamente a capacidade de cada ferramenta fornecer uma visualização da participação do consumidor. Para sistematizar esta análise, considerou-se que o mapeamento de um processo deve proporcionar a visualização de 5 aspectos fundamentais à sua compreensão e execução, quais sejam, i) propósito, ii) local, iii) sequência, iv) agente responsável e v) modo ou meio aplicado referentes ao fluxo de processo objeto de estudo, os quais podem ser elucidados por meio de questões do tipo i) What (o que é feito?) e Why (por que é feito?), ii) Where (onde é feito?), iii) When (quando é feito?), iv) Who (quem faz?) e v) How (como é feito?), respectivamente (Kanawaty, 1992; Lee \& Snyder, 2006). Neste estudo, esta relação foi ampliada para cobrir os 7 aspectos que o método 5W2H (Smith, 1998; Daychoum, 2007) preconiza para a descrição de uma dada situação, desdobrando "propósito" em "ações" que compõem o processo e "motivações" que levam à sua realização, as quais podem ser elucidadas por questões do tipo What e Why, respectivamente; e pela inclusão do aspecto "medida", que pode ser elucidado por meio de questões do tipo How much (quanto?) para verificar se a aplicação da ferramenta considerada envolve medição.

Para operacionalizar a análise comparativa, com base em exemplos de questões derivadas dos 5W2H sugeridos por Kanawaty (1992) e Daychoum (2007), uma abrangente relação de 38 tipos de dados específicos que caracterizam os 7 principais aspectos de um processo foi definida. Dado que a motivação desta análise é avaliar como cada ferramenta contribui para a visualização da experiência do consumidor no processo focado, para cada aspecto, pelo menos uma questão foi formulada considerando o ponto de vista do consumidor. Os tipos de dados considerados são especificados na Tabela 1. Nas figuras que são apresentadas na seção 4 ilustrando a aplicação dessas ferramentas, exemplos de diferentes tipos de dados 
Tabela 1. Tipos de dados sobre o processo que as ferramentas de mapeamento podem representar.

\begin{tabular}{|c|c|c|c|c|c|c|}
\hline $\begin{array}{l}\text { Aspecto do } \\
\text { processo }\end{array}$ & $\begin{array}{c}\text { Item } \\
\text { do } \\
5 \mathrm{~W} 2 \mathrm{H}\end{array}$ & $\begin{array}{l}\text { Tipo de } \\
\text { questão }\end{array}$ & \# & $\begin{array}{l}\text { G ou } \\
C^{*}\end{array}$ & Tipo de dado & Abreviatura \\
\hline \multirow{8}{*}{ 1. Ação } & \multirow{8}{*}{ What } & \multirow{8}{*}{$\begin{array}{l}0 \text { que é } \\
\text { feito? }\end{array}$} & 1 & G & Atividade & $A$ \\
\hline & & & 2 & G & Atividades síncronas (simultâneas) ou paralelas & As \\
\hline & & & 3 & G & Atividade alternativa (execução condicionada a uma decisão) & Aa \\
\hline & & & 4 & G & Atividade que envolve julgamento & $A j$ \\
\hline & & & 5 & G & Visão detalhada no nível de microatividade & Ad \\
\hline & & & 6 & G & Processo de suporte (infraestrutura do provedor) & $P$ \\
\hline & & & 7 & G & Noção se uma atividade do consumidor é visível (ou não) para o provedor & $V p$ \\
\hline & & & 8 & C & Noção se uma atividade do provedor é visível (ou não) para o consumidor & $V c$ \\
\hline \multirow{4}{*}{ 2. Motivação } & \multirow{4}{*}{ Why } & \multirow{4}{*}{$\begin{array}{c}\text { Por que é } \\
\text { feito? }\end{array}$} & 9 & G & Saída (output) fornecida por uma atividade & $O$ \\
\hline & & & 10 & G & Tomada de decisão & $D$ \\
\hline & & & 11 & G & Indicação de looping ou retrabalho & Lo \\
\hline & & & 12 & C & Evidências físicas de uma atividade (para o consumidor) & $P e$ \\
\hline \multirow{5}{*}{ 3. Agente } & \multirow{5}{*}{ Who } & \multirow{5}{*}{$\begin{array}{l}\text { Quem } \\
\text { faz? }\end{array}$} & 13 & G & Fornecedor de recurso (supplier) & $S$ \\
\hline & & & 14 & G & Indicação de que a atividade é executada por um provedor & $A p$ \\
\hline & & & 15 & G & Indicação de que a atividade é executada por uma máquina/um sistema & $A m$ \\
\hline & & & 16 & C & Indicação de que a atividade é executada pelo consumidor & Ac \\
\hline & & & 17 & C & Interação do consumidor com outra(s) entidade(s), além do provedor principal & $E$ \\
\hline \multirow{3}{*}{ 4. Local } & \multirow{3}{*}{ Where } & \multirow{3}{*}{$\begin{array}{l}\text { Onde é } \\
\text { feito? }\end{array}$} & 18 & G & Distinção de diferentes locais onde o provedor executa suas atividades & $L p$ \\
\hline & & & 19 & C & Distinção de diferentes locais onde o consumidor executa suas atividades & $L c$ \\
\hline & & & 20 & C & Local de execução da atividade (se local do consumidor ou do provedor) & $L$ \\
\hline \multirow{5}{*}{ 5. Sequência } & \multirow{5}{*}{ When } & \multirow{5}{*}{$\begin{array}{l}\text { Quando é } \\
\text { feito? }\end{array}$} & 21 & G & Ramificação do fluxo de atividades (branching) & $B$ \\
\hline & & & 22 & G & Convergência de fluxos de atividades & $C$ \\
\hline & & & 23 & G & Relação de precedência entre um par de atividades (forte no curto prazo) & $P_{S}$ \\
\hline & & & 24 & G & Relação de precedência entre um par de atividades (com maior defasagem) & $P l$ \\
\hline & & & 25 & C & Momento de transição em que o consumidor aciona o provedor ou vice-versa & $T t$ \\
\hline \multirow{7}{*}{ 6. Modo/meio } & \multirow{7}{*}{ How } & \multirow{7}{*}{$\begin{array}{l}\text { Como é } \\
\text { feito? }\end{array}$} & 26 & G & Entrada (input) recebida por uma atividade & 1 \\
\hline & & & 27 & G & Execução de atividade independentemente de outra entidade & $A i$ \\
\hline & & & 28 & G & Execução de atividade interagindo indiretamente com outra entidade & $A n$ \\
\hline & & & 29 & G & Execução de atividade interagindo diretamente com outra entidade & $A r$ \\
\hline & & & 30 & C & Fornecimento de recurso pelo consumidor & $R c$ \\
\hline & & & 31 & C & Ocorrência de espera para o consumidor & W \\
\hline & & & 32 & C & Meio de contato entre consumidor e provedor & $M$ \\
\hline \multirow{6}{*}{ 7. Medida } & \multirow{6}{*}{$\begin{array}{l}\text { How } \\
\text { much }\end{array}$} & \multirow{6}{*}{ Quanto? } & 33 & G & Duração do tempo de uma atividade & $\mathrm{Ta}$ \\
\hline & & & 34 & G & Duração do tempo de espera (wait) & $T w$ \\
\hline & & & 35 & G & Nivel do impacto para a proposta de valor do provedor & $P v$ \\
\hline & & & 36 & G & Medidas de desempenho do processo (performance) & $P f$ \\
\hline & & & 37 & C & Nível de agregação de valor na atividade (para o consumidor) & $V a$ \\
\hline & & & 38 & C & Nível de satisfação do consumidor com a atividade & Cs \\
\hline
\end{tabular}

*G: dado de descrição geral ou específico a uma entidade que não o consumidor. C: dado específico à participação ou perspectiva do consumidor.

capturados por cada ferramenta são apontados por meio de balões preenchidos com uma abreviatura que identifica o tipo de dado a que se refere, conforme a correspondência apresentada na Tabela 1.

Assim, as ferramentas de mapeamento focadas serão analisadas em relação à capacidade de registrar e informar cada um destes tipos de dados para representar o processo mapeado. Para avaliar a forma como tais dados descritivos são representados por cada ferramenta, foi adotado o critério de classificação ordinal descrito na Tabela 2. Este critério considera uma classificação em 3 níveis, como no procedimento adotado por Santos \& Varvakis (2002), para avaliação de técnicas de representação de processos de serviços em geral. Para possibilitar tratar quantitativamente os níveis atribuídos, no presente trabalho, estes foram associados a uma pontuação que varia de 0 a 1 , o que permite gerar para cada um dos 7 principais aspectos do processo objeto do mapeamento uma avaliação quanto ao grau GRF com que é representado por uma dada ferramenta com base no indicador definido pela Equação 1:

$G R F_{i}=\frac{\sum_{j=1}^{n_{i}} G R_{i j}}{n_{i}}$

onde: $n_{\mathrm{i}}=$ número de tipos de dados descritivos do aspecto $i$, e $G R_{\mathrm{ij}}=$ grau com que o $j$-ésimo tipo de dado referente ao aspecto $i$ é representado pela ferramenta. 
Tabela 2. Critério de classificação do grau de representação (GR) dos dados de processo.

\begin{tabular}{|c|c|c|}
\hline Nivel & Descrição & $\begin{array}{l}\text { Escala de } \\
\text { pontuação }\end{array}$ \\
\hline Pleno & $\begin{array}{l}0 \text { dado pode ser graficamente representado na figura da ferramenta: isso possibilita que o dado seja } \\
\text { percebido visualmente, desde que se conheçam as convenções gráficas da ferramenta considerada }\end{array}$ & 1 \\
\hline Intermediário & $\begin{array}{l}0 \text { dado pode ser registrado pela ferramenta, mas somente por meio de uma descrição textual: isso } \\
\text { implica que, caso haja uma descrição textual que direta ou indiretamente se refira ao dado, este } \\
\text { poderá ser extraído da ferramenta considerada desde que lido }\end{array}$ & 0,5 \\
\hline Nulo & 0 dado não é capturado pela ferramenta & 0 \\
\hline
\end{tabular}

Para realizar uma avaliação geral da capacidade informativa das 7 ferramentas aqui abordadas de forma comparativa, foi adotada a abordagem SMOP proposta por Schütz et al. (1998) para avaliar o desempenho global com base em múltiplos indicadores explorando a técnica de exibição destes por meio de um gráfico radar com múltiplos eixos radiais. A utilização do gráfico radar proporciona um meio simples de visualização integrada de múltiplos indicadores quando os pontos que indicam os valores destes indicadores plotados nos eixos são conectados com linhas retas formando um polígono. Caso estes valores estejam normalizados no intervalo de 0 a 1, a abordagem SMOP considera que a medição da superfície deste polígono fornece uma medida única que sintetiza o desempenho nos múltiplos indicadores num indicador de desempenho global pela aplicação da Equação 2:

$$
S M O P=\left(\begin{array}{l}
\left(I_{1} * I_{2}\right)+\left(I_{2} * I_{3}\right)+\left(I_{3} * I_{4}\right)+ \\
\left(I_{4} * I_{5}\right)+\ldots+\left(I_{n} * I_{1}\right)
\end{array}\right) * \operatorname{sen}\left(360^{\circ} / n\right) / 2
$$

onde: $n=$ número de indicadores (eixos) representados no gráfico radar, e $l_{\mathrm{i}}=$ distância entre o vértice do polígono plotado sobre o eixo do indicador $i$ e o centro do gráfico (corresponde ao valor do indicador).

Esta medida, chamada de surface measure of overall performance (SMOP), possibilita que o desempenho global seja expresso quantitativamente e assim balizar avaliações não apenas visuais. 0 SMOP é um índice composto do tipo "quanto maior, melhor" que gera valores adimensionais abstratos (Schütz et al., 1998), mas que podem ser comparados entre si e ordenados, e assim serem interpretados relativamente, o que tem motivado sua aplicação em estudos de benchmarking em diferentes setores (Martin \& Román, 2006; Tiku et al., 2007; Mohan \& Sinciya, 2013). Para fins da avaliação comparativa das ferramentas aqui consideradas, para cada ferramenta será construído um gráfico radar a partir das avaliações atribuídas aos graus com que representam os 7 principais aspectos do processo e sua capacidade informativa será medida pelo valor de SMOP correspondente, considerando como valores de $I_{\mathrm{i}}$ os valores atribuídos aos $G R F_{i}$.

\section{Ferramentas de mapeamento das atividades do consumidor}

Nesta seção, 7 das principais ferramentas de mapeamento de processos de serviço encontradas na literatura, quais sejam, SIPOC, Fluxograma, Blueprint, PCN, Mapa do Consumo, SERVPRO e Carta de Atividades, são apresentadas procurando-se destacar suas principais características. Embora, em termos funcionais, elas se assemelhem por servirem basicamente à visualização das atividades que compõem um processo de forma sequencial, como cada ferramenta apresenta características diagramáticas próprias e faz uso de um conjunto limitado de dados, elas possibilitam observar um mesmo processo sob diferentes enfoques e níveis de profundidade.

\subsection{SIPOC}

O SIPOC (Suppliers, Inputs, Process, Outputs, Customers) é um mapa de alto nível que possibilita a visualização do processo estudado e de seus principais componentes (Stevens, 1996; Rasmusson, 2006). É estruturado em cinco colunas, nas quais são apontados, da esquerda para direita: os fornecedores envolvidos (suppliers), as entradas necessárias (inputs), o processo em análise (process), as saídas do processo (outputs) e os clientes atendidos pelo processo (customers). Trata-se de uma ferramenta versátil, cuja aplicação é muito explorada no planejamento de melhorias de processos com base em metodologias como Lean e Seis Sigma, tanto na área de manufatura como na de serviços (George, 2003; Koning et al., 2008).

Em sua forma de aplicação convencional, o SIPOC inclui na quinta coluna os clientes internos ou externos a serem atendidos no desenrolar do processo. Assim, quando o processo considerado entrega algum bem, serviço ou informação ao consumidor, este deve constar como um dos clientes. Caso conste, o preenchimento da quarta coluna, deve-se identificar as saídas específicas destinadas ao consumidor. Além disso, como em muitos processos de negócio a organização necessita obter dados ou decisões dos consumidores, é muito comum que estes sejam identificados no SIPOC como fornecedores a serem acionados para 
a coleta de tais entradas. Assim, a aplicação desta ferramenta possibilita visualizar diferentes formas como uma organização pode se relacionar com o consumidor através de seus processos.

No contexto de processos de serviços, os recursos necessários podem ser disponibilizados pela empresa prestadora do serviço, mas muitas vezes o próprio consumidor precisa dispor de parte considerável destes. Neste caso, ainda que seja menos convencional, o SIPOC pode ser diagramado explicitando os recursos que o consumidor necessita ter disponível para poder executar as tarefas que lhe são atribuídas no processo. Entre tais recursos incluem-se não somente bens, mas também conhecimentos e habilidades que o consumidor deve possuir para conseguir executar as tarefas que lhe cabem no processo e atingir o resultado desejado, o que implica num custo para ele. Quando isso ocorre, o SIPOC pode ser aplicado posicionando o consumidor na primeira coluna e os recursos que precisa fornecer na segunda coluna, para evidenciar que ele é responsável por aqueles.

\subsection{Fluxograma}

0 Fluxograma é uma ferramenta de uso amplamente disseminado que pode ser aplicada na descrição de diversos tipos de fluxos sequenciais, como o fluxo das atividades que compõem um processo organizacional ou um projeto, dos materiais em processos de manufatura, das instruções que compõem um algoritmo computacional, e dos dados que fluem num sistema, por meio do encadeamento de símbolos, como o retângulo para representar atividades e o losango para representar tomadas de decisão (Krajewski et al., 2009; Nakatsu, 2010). Contudo, embora as organizações se empenhem em aplicá-lo objetivamente no projeto de novos processos ou na revisão de processos existentes, procurando adequar a sua implantação ou racionalização às suas próprias necessidades e condições, a aplicação do Fluxograma para mapear o fluxo ao qual os consumidores têm de se submeter para conseguir acesso a um bem ou serviço oferecido pela organização é pouco difundida. Nesta direção, certos autores lembram que mesmo na aplicação de Fluxogramas para mapear processos sob o ponto de vista da empresa, é importante procurar identificar onde os consumidores podem interagir com algum agente da empresa e como as atividades desempenhadas pela empresa podem influenciar na satisfação do consumidor (Madison, 2005; McLean-Conner, 2006).

Há diferentes tipos de Fluxogramas. Para aplicá-los de modo a incorporar a experiência do consumidor, o tipo mais apropriado é o que considera a realização de atividades por múltiplos agentes, adotando "raias" que indicam as entidades responsáveis pela execução das atividades. Desta forma, o consumidor como agente participante do processo pode ser associado a uma das raias, e as atividades por ele executadas encadeadas ao longo desta raia (Damelio, 2011). Por convenção, cada atividade pode ser posicionada somente em uma raia para explicitar que a responsabilidade pela sua execução cabe à entidade associada à raia em que se encontra.

\subsection{Blueprint}

Esta ferramenta de mapeamento possibilita visualizar a participação do consumidor num processo produtivo e os pontos de interação entre ele e a empresa provedora do serviço. "0 blueprint de serviços é um mapa ou fluxograma de todas as transações integrantes do processo de prestação do serviço." (Fitzsimmons \& Fitzsimmons, 2005, p. 95).

Para Shostack (1987), o Blueprint é uma técnica de mapeamento de processos de serviço que, ao contemplar as relações entre os agentes envolvidos no processo evidenciando os pontos de interação entre consumidor e provedor, auxilia a identificação de oportunidades de melhoria.

Os mapas gerados pela aplicação desta ferramenta apresentam as atividades que compõem o processo encadeadas em sequência cronológica na direção horizontal, ao passo que as atividades realizadas pelas diferentes partes envolvidas no processo são separadas na direção vertical (Fliess \& Becker, 2006). Desta forma, o Blueprint de serviços é geralmente diagramado ao longo de cinco faixas horizontais que são preenchidas para representar os seguintes elementos:

a) Ações do consumidor: atividades executadas pelo consumidor que evidenciam o grau de envolvimento e coparticipação dele para atingir o resultado do serviço.

b) Ações da linha de frente (onstage): atividades executadas pela organização provedora do serviço que ocorrem na linha de frente, "no palco", e que, portanto, são percebidas pelo consumidor. Durante a execução destas atividades, mesmo que não ocorra uma interação face a face entre um funcionário da empresa e o consumidor, aquilo que este puder enxergar pode influenciar sua percepção em relação ao serviço prestado. As ações da linha de frente são separadas das ações do consumidor pela "linha de interação" e sempre que ela é cruzada por uma linha vertical isso indica a ocorrência de um contato entre o consumidor e o provedor, também denominado de "encontro de serviço" (Solomon et al., 1985) ou "momento da verdade" (Bitner et al., 2008). 
c) Ações da retaguarda (backstage): são também atividades desempenhadas pela organização provedora do serviço, porém não são vistas pelo consumidor e não envolvem contato direto com ele. As atividades executadas pela empresa na linha de frente e na retaguarda são separadas pela "linha de visibilidade". As atividades posicionadas acima desta linha estão expostas ao consumidor exercendo maior influência na percepção deste em relação ao serviço. Já as que se encontram abaixo desta linha não são vistas pelo consumidor.

d) Processos de suporte: processos de apoio que precisam ocorrer para que o serviço seja fornecido. Representam áreas ou sistemas de suporte ao processo mapeado e são alocados no Blueprint abaixo da "linha interna de interação". As conexões entre as atividades da retaguarda e os processos de suporte (representadas por linhas verticais) mostram interações interfuncionais.

e) Evidências físicas: são os fatores ou aspectos observáveis que fazem parte da experiência do serviço percebida pelo consumidor.

\subsection{Process-Chain-Network}

A ferramenta Process-Chain-Network (PCN) foi desenvolvida por Sampson (2012) para representar processos que envolvem interações entre provedores de serviço e consumidores, revelando aspectos da sua complexidade que não são explicitados por ferramentas como Blueprint e Fluxograma. Para isso, o mapeamento de processos de serviço por meio desta ferramenta parte da premissa de que, se múltiplas entidades constituem um sistema de serviço, é preciso representar como as ações executadas por elas compõem cadeias de processo que se entrelaçam formando uma "rede de valor" (daí sua denominação referir à tríade Processo(adeia-Rede), não se restringindo à visualização de processos em que o consumidor interage com uma única entidade.

Para enriquecer a descrição da natureza das ações que ocorrem no domínio de uma entidade, esta abordagem admite que as ações podem ser divididas conforme a necessidade de envolver interação com outra(s) entidade(s). Assim, quando uma ação envolve interação, ela distingue se isso ocorre de forma direta (com contato pessoal entre agentes das partes envolvidas) ou indireta (por intermédio de recurso próprio ou disponibilizado pela outra parte), e quando não, indica que pode ser processada independentemente. 0 Blueprint distingue ações de linha de frente e de retaguarda, mas somente para o provedor. A PCN faz a distinção da natureza das ações de todas as entidades, inclusive as do consumidor, não se limitando a contemplar o aspecto da visibilidade, mas caracterizando o grau de dependência entre as ações.

$\mathrm{Na}$ diagramação dos processos mapeados, a PCN considera que as ações desenvolvidas no domínio de cada entidade podem ser estruturadas conforme ilustra a Figura 1, estabelecendo cinco colunas distintas que definem a existência de regiões em que ações são executadas com três diferentes graus de interação com as demais entidades da rede de valor. Nas colunas das duas bordas laterais são posicionadas as ações que envolvem interação direta com outra entidade, na coluna central são posicionadas as ações independentes sobre as quais a entidade possui maior grau de controle, e nas duas colunas entre a central e as das bordas são posicionadas as ações que envolvem interação indireta. Nas colunas à esquerda e à direita da central são representadas as interações, respectivamente, com o(s) fornecedor(es) e com o(s) cliente(s) da entidade focada.

$\mathrm{Na}$ descrição de cadeias de processos seguindo as convenções da PCN, as setas usadas para interligar duas ações indicam a relação de dependência existente entre elas. 0 seu sentido pode representar que algo é transferido de uma para outra, mas não necessariamente, pois pode haver uma relação apenas temporal sem envolver fluxo. Quando a aplicação da PCN é motivada para examinar a influência das ações mapeadas sobre as propostas de valor envolvidas, as ações que trazem benefício ao consumidor (i.e. agregam valor por contribuir para satisfazer uma necessidade) são marcadas com (-) e ações que

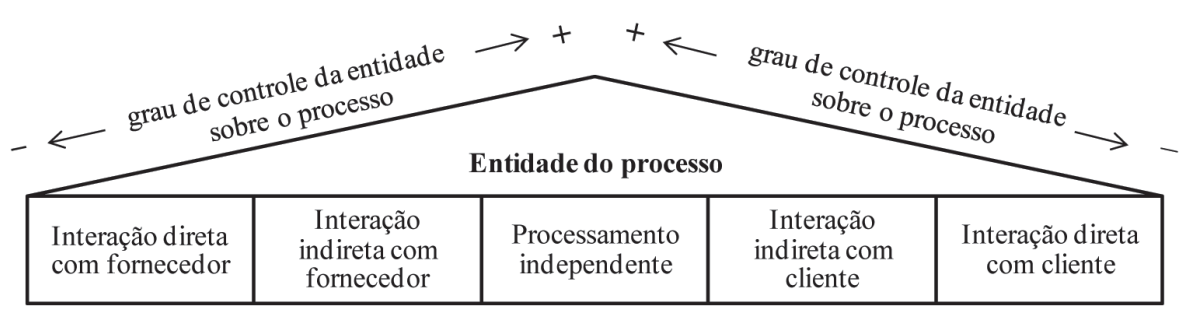

Figura 1. Estrutura de construção da ferramenta Process-Chain-Network (PCN). 
exigem um esforço não financeiro do consumidor (e.g. por causar uma inconveniência) são marcadas com *). Já as ações nas quais incorrem custos ao fornecedor e aquelas nas quais o fornecedor recebe uma recompensa financeira são marcadas com $-\$$ com $+\$$, respectivamente.

\subsection{Mapa do consumo}

O Mapa do Consumo proposto por Womack \& Jones (2006) identifica as atividades executadas no gemba do consumidor. Esta forma de mapa deriva do método de mapeamento do fluxo de valor (value stream mapping) amplamente utilizado para levantamento do estado atual de um processo e proposição de um estado melhorado em iniciativas de implementação da metodologia lean. A aplicação desta ferramenta facilita não apenas a visualização das atividades executadas pelos consumidores, mas também a identificação de oportunidades para reduzir esforço e tempo requeridos do consumidor e melhorar sua percepção de valor no processo.

Womack \& Jones (2006) ressaltam a importância de observar o processo de serviço de forma abrangente, representando de maneira emparelhada o fluxo das atividades da empresa, num mapa denominado Mapa de Provisão (provision map), e o fluxo das atividades do consumidor num mapa denomidado Mapa do Consumo (consumption map), para possibilitar o reconhecimento de oportunidades de melhoria no fluxo de ambas as partes. A construção do Mapa do Consumo e do Mapa de Provisão é baseada em diversos recursos gráficos. Nestes mapas, as atividades são representadas por blocos cuja área representa 0 tempo que demandam. A ocorrência de interações entre consumidor e provedor é identificada por setas que conectam seus fluxos de atividades, as quais podem ser complementadas por figuras que ilustram a forma como o contato é estabelecido. A parcela do bloco destacada em cinza representa o tempo gasto pelo consumidor em atividades que são importantes para ter a sua necessidade atendida ou o tempo gasto pelo provedor em atividades nas quais trabalhou com satisfação, enquanto a parcela em branco representa o tempo gasto em atividades ineficazes que não agregam valor. Para indicar o grau de satisfação ou incômodo das pessoas que executam as atividades nos processos mapeados, são inseridas imagens de expressões faciais.

Por meio do Mapa do Consumo, Womack \& Jones (2006) procuram estender a aplicação dos conceitos da filosofia lean para a avaliação das atividades desempenhadas pelos consumidores. Estes autores propõem que os tempos despendidos pelos consumidores sejam analisados de forma crítica e que se busque uma clara distinção dos momentos em que o consumidor teve prazer em participar do processo, daqueles em que isso não ocorreu, de forma a melhorar a prestação do serviço. As atividades atribuídas aos consumidores nem sempre são complexas, mas exigem deles tempo e recursos que poderiam ser mais bem utilizados em atividades que lhes dessem prazer. "Mesmo atividades simples de consumo envolvem muitas etapas e muito tempo do consumidor. E a maior parte deste tempo é desperdiçada." (Womack \& Jones, 2006, p. 15).

\subsection{SERVPRO}

A ferramenta de mapeamento e diagnóstico de processo SERVPRO baseia-se no IDEF3 - técnica desenvolvida pela Força Aérea dos Estados Unidos para descrever, especificar e modelar sistemas de manufatura - porém, tendo como foco as atividades desempenhadas pelo consumidor ao longo dos processos de serviço (Santos \& Varvakis, 2002).

Esta ferramenta envolve a construção de um diagrama e o detalhamento de atividades por meio de documentos de elaboração. 0 diagrama apresenta o fluxo de atividades executadas pelo consumidor de forma gráfica e sequencial, utilizando as junções \& ("e"), quando as atividades relacionadas ocorrem paralelamente; 0 ("e/ou"), quando dentre as atividades relacionadas ocorre somente uma ou mais de uma paralelamente, e X ("ou”), quando somente uma das atividades apontadas ocorre; e o elemento "Go-to" para direcionar o fluxo a uma atividade já descrita anteriormente.

0 documento de elaboração serve para detalhar uma atividade apresentada no diagrama e pode ser aplicado às atividades que merecem uma análise mais específica. Neste documento são apontados os recursos ou "elementos" - conforme a nomenclatura adotada por Santos \& Varvakis (2002) - identificados na atividade que entram em contato com o consumidor e que, portanto, podem influenciar sua percepção do serviço, bem como parâmetros denominados

$$
\begin{aligned}
& \text { | } \rightarrow \text { Ação do cliente. } \\
& \leftarrow \text { Reação do cliente. } \\
& \text { 㱐 } \rightarrow \text { Ação do sistema de serviços. } \\
& \leftarrow \text { 亚 Reação do sistema de serviços. }
\end{aligned}
$$

Figura 2. Ícones para indicar a interação entre cliente e sistema. Fonte: Santos \& Varvakis (2002, p. 42). 
"determinantes da qualidade", que descrevem a qualidade do serviço segundo critérios do cliente, e medidas de desempenho que tangibilizem tais determinantes. Adicionalmente, identifica as interações que ocorrem entre cliente e sistema de serviço utilizando os ícones indicados na Figura 2 para caracterizar as ações ou reações executadas por cada parte.

\subsection{Carta de atividades}

A Carta de Atividades é amplamente utilizada em estudos de tempos e métodos para planejamento e controle de operações, e caracteriza-se por fornecer uma visão detalhada da interação entre os recursos de produção na execução de determinadas atividades de um processo (Corrêa \& Corrêa, 2004). Na área industrial, onde é mais conhecida pela denominação Diagrama Homem-Máquina, esta ferramenta é usada para descrever e analisar a interação entre operador(es) e máquina(s) para identificar tempos ociosos e ocupá-los de forma mais eficiente (Barnes, 1977).

Expandindo sua aplicação para a área de serviços, a Carta de Atividades pode auxiliar na análise das atividades que compõem um processo de senviço envolvendo diversas combinações de agentes ou recursos como: operador e cliente; operador e máquina; cliente e máquina; ou ainda operador, cliente e máquina. Cada recurso envolvido no processo é posicionado em uma coluna da Carta de Atividades. Ao longo de cada coluna, as atividades do processo alocadas ao recurso correspondente são enumeradas em ordem cronológica de cima para baixo. Usualmente, adota-se uma escala de tempo que possibilita visualizar o tempo gasto pelos recursos em cada atividade. Quando um recurso não está envolvido na execução de determinada atividade, indica-se a ociosidade deste, ou seja, que está em espera (Summers, 1998).

Esta ferramenta é, portanto, aplicável na identificação e medição das atividades executadas pelos consumidores, podendo ser utilizada para indicar o tempo gasto por um consumidor em um processo de serviço e evidenciar os momentos em que este fica esperando a execução de uma atividade por um operador ou por uma máquina (sistema) da empresa provedora.

\subsection{Aplicabilidade das ferramentas de mapeamento para captura da experiência do consumidor}

Dentre as ferramentas discutidas nas seções 3.1 a 3.7, somente o PCN, o SERVPRO e o Mapa do Consumo, introduzidas mais recentemente, foram concebidas para promover a construção de uma perspectiva mais centrada na visão e experiência do consumidor.

0 Blueprint, embora inclua a representação do fluxo do consumidor e suas interações, é usualmente mais explorado como ferramenta que fornece uma visão funcional e processual que é muito apreciada no projeto, organização e controle do processo de serviço sob a perspectiva da empresa. Contudo, mais recentemente, passou a ser citado por artigos que também o valorizam como um meio para visualizar o papel do consumidor, apresentando esta forma de aplicação em casos práticos (Kumar et al., 2008; 2010; Kumar \& Steinebach, 2008).

Já a aplicação do SIPOC e Fluxograma tem sido, convencionalmente, motivada pela necessidade de desenvolver projetos e planejar processos de negócio da empresa, e a da Carta de Atividades para racionalizar o uso de seus recursos, ou seja, tais ferramentas têm sido aplicadas primordialmente como meios para suportar a lógica convencional de aprimorar o controle de condições e fatores internos à empresa. Contudo, no que tange à motivação para sua aplicação, é viável aproveitar a estrutura analítica e os recursos de representação gráfica destas ferramentas na função de capturar a experiência do consumidor e, assim, enxergar como oferecer um processo de serviço que lhe seja também mais efetivo e vantajoso.

\section{Aplicação das ferramentas de mapeamento em um processo de compra pela internet}

Com o propósito de ilustrar como as ferramentas de mapeamento SIPOC, Fluxograma, Blueprint, PCN, Mapa do Consumo, SERVPRO e Carta de Atividades podem ser aplicadas na construção de mapas que possibilitem a visualização das atividades desempenhadas pelos consumidores em processos de serviço, nesta seção estas ferramentas são aplicadas na construção de um conjunto de mapas para representação de um processo de serviço do tipo "faça você mesmo", em que o consumidor assume grande responsabilidade na execução do processo.

Os mapas apresentados nas figuras que seguem referem-se ao processo de compra pela internet observado pelos pesquisadores e fornecem diferentes perspectivas de uma mesma sequência de atividades. Em cada figura, foram sobrepostos balões preenchidos com abreviaturas definidas na Tabela 1 para apontar exemplos de dados referentes aos principais aspectos do processo representado que cada ferramenta é capaz de registrar e informar. 


\begin{tabular}{|c|c|c|c|c|}
\hline Fornecedores & Entradas & Processo & Saídas & Clientes \\
\hline \multirow{3}{*}{ Consumidor } & Fonte de energia & \multirow{5}{*}{$\begin{array}{l}\text { 1. Entra no site e } \\
\text { seleciona item } \\
\text { para compra }\end{array}$} & \multirow{6}{*}{$\begin{array}{l}\text { Item selecionado para } \\
\text { compra }\end{array}$} & \multirow{6}{*}{$\begin{array}{l}\text { Consumidor que realiza } \\
\text { compra via internet }\end{array}$} \\
\hline & Computador & & & \\
\hline & Acesso a internet & & & \\
\hline \multirow{3}{*}{$\begin{array}{l}\text { Empresa fornecedora } \\
\text { do produto comprado } \\
\text { pela internet }\end{array}$} & Site que oferta o produto & & & \\
\hline & Dado da disponibilidade do produto & & & \\
\hline & Sistema para recebimento do pedido & \multirow{7}{*}{$\begin{array}{l}\text { 2. Executa o } \\
\text { pagamento }\end{array}$} & & \\
\hline \multirow{4}{*}{ Consumidor } & Fonte de energia & & \multirow{7}{*}{ Pagamento confirmado } & \multirow{5}{*}{$\begin{array}{l}\text { Consumidor que realiza } \\
\text { compra via internet }\end{array}$} \\
\hline & Computador & & & \\
\hline & Acesso a internet & & & \\
\hline & Cartão de crédito & & & \\
\hline \multirow{2}{*}{$\begin{array}{l}\text { Empresa fornecedora } \\
\text { do produto comprado } \\
\text { pela internet }\end{array}$} & Sistema para recebimento do pedido & & & \\
\hline & $\begin{array}{l}\text { Base de dados para armazenamento } \\
\text { das informações do cliente }\end{array}$ & & & \multirow{2}{*}{$\begin{array}{l}\text { Área financeira da empresa } \\
\text { fornecedora do produto }\end{array}$} \\
\hline $\begin{array}{l}\text { Empresa de processamento } \\
\text { de pagamento via internet }\end{array}$ & $\begin{array}{l}\text { Site que processa o pagamento de } \\
\text { forma segura }\end{array}$ & & & \\
\hline \multirow{5}{*}{ Consumidor } & Fonte de energia & & \multirow{4}{*}{$\begin{array}{l}\text { Comprovante da aquisição } \\
\text { do produto }\end{array}$} & \multirow{4}{*}{$\begin{array}{l}\text { Consumidor que realiza } \\
\text { compra via internet }\end{array}$} \\
\hline & Computador & & & \\
\hline & Impressora & \multirow{3}{*}{$\begin{array}{l}\text { 3. Confirma } \\
\text { a compra }\end{array}$} & & \\
\hline & Acesso a internet & & & \\
\hline & Conta de e-mail & & \multirow{3}{*}{$\begin{array}{l}\text { Solicitação de envio do } \\
\text { produto adquirido pelo } \\
\text { consumidor }\end{array}$} & \multirow{3}{*}{$\begin{array}{l}\text { Área de armazenamento dos } \\
\text { produtos }\end{array}$} \\
\hline \multirow{2}{*}{$\begin{array}{l}\text { Empresa fornecedora } \\
\text { do produto comprado } \\
\text { pela internet }\end{array}$} & Sistema para recebimento do pedido & & & \\
\hline & $\begin{array}{l}\text { Base de dados para armazenamento } \\
\text { das informações do cliente }\end{array}$ & & & \\
\hline \multirow{2}{*}{$\begin{array}{l}\text { Empresa fornecedora } \\
\text { do produto comprado } \\
\text { pela internet }\end{array}$} & $\begin{array}{l}\text { Base de dados para armazenamento } \\
\text { das informações do cliente }\end{array}$ & $\downarrow$ & \multirow{3}{*}{$\begin{array}{l}\text { Produto entregue no local } \\
\text { determinado pelo cliente }\end{array}$} & \multirow{3}{*}{$\begin{array}{l}\text { Consumidor que realiza } \\
\text { compra via internet }\end{array}$} \\
\hline & $\begin{array}{l}\text { Funcionário que monta e envia o } \\
\text { pedido de compra }\end{array}$ & \multirow[t]{2}{*}{ 4. Recebe produto } & & \\
\hline Correios & $\begin{array}{l}\text { Funcionário que entrega o produto ao } \\
\text { cliente }\end{array}$ & & & \\
\hline
\end{tabular}

Figura 3. SIPOC do processo de compra pela internet.

Esses mapas são apresentados numa sequência que ilustra as visões progressivamente mais profundas a serem buscadas na condução dos passos 3 e 4 do roteiro geral de mapeamento resumido na seção 2 . Inicialmente, é apresentado o mapa do SIPOC, que é o de nível mais alto, e em seguida são apresentados os mapas obtidos com as demais ferramentas, terminando com o da Carta de Atividades que permite examinar as atividades consideradas no nível de suas microatividades.

$\mathrm{Na}$ Figura 3, observa-se a visão mais macro do mapa do SIPOC, que delimita as fronteiras do objeto de estudo, ou seja, o início e fim do fluxo do processo de compra via internet considerado. As macroatividades que compõem o processo são enumeradas na coluna "processo". Embora esta forma de visualização não detalhe o procedimento de execução das atividades desempenhadas pelo consumidor, ela possibilita visualizar os recursos necessários para a concretização do processo. Pelo exemplo apresentado, verifica-se que mesmo para um processo simples e com nenhuma ou pouca possibilidade de ramificação (que causariam variações de fluxo), pode ser necessário fornecer múltiplas entradas para se atingir o resultado desejado pelo consumidor. Este mapa evidencia que o consumidor não atua apenas como cliente, mas também como um fornecedor-chave que tem de dispor de diversos recursos próprios para poder concretizar o processo de compra.

A aplicação do Fluxograma para a representação deste processo de compra pela internet é apresentada na Figura 4. Como existem diferentes softwares que facilitam a diagramação desta ferramenta, um deles - o Visio Basic, que permite gerar a versão com atividades separadas por raias - foi usado na elaboração desta figura, destinando uma raia para a representação das atividades executadas pelo consumidor. As demais raias referem-se às atividades executadas por entidades envolvidas no fornecimento do serviço. A macroatividade "1" descrita na Figura 3 foi desdobrada em 3 atividades mais específicas $(1.1,1.2$ e 1.3$)$ na representação com o Fluxograma. Analogamente, as macroatividades "2", "3" e " 4 " foram desdobradas, respectivamente, em 3, 2 e 2 atividades. Assim, este exemplo ilustra uma visão mais detalhada do fluxo que pode ser capturada com Fluxogramas. $\mathrm{Na}$ Figura 4, a relação direta entre as macroatividades e as atividades detalhadas é evidenciada por meio de linhas de fronteira verticais que delimitam o fim de cada macroatividade.

A Figura 5 mostra o mapa de Blueprint para o processo considerado. Neste mapa, as atividades realizadas pelo consumidor são alocadas na raia 


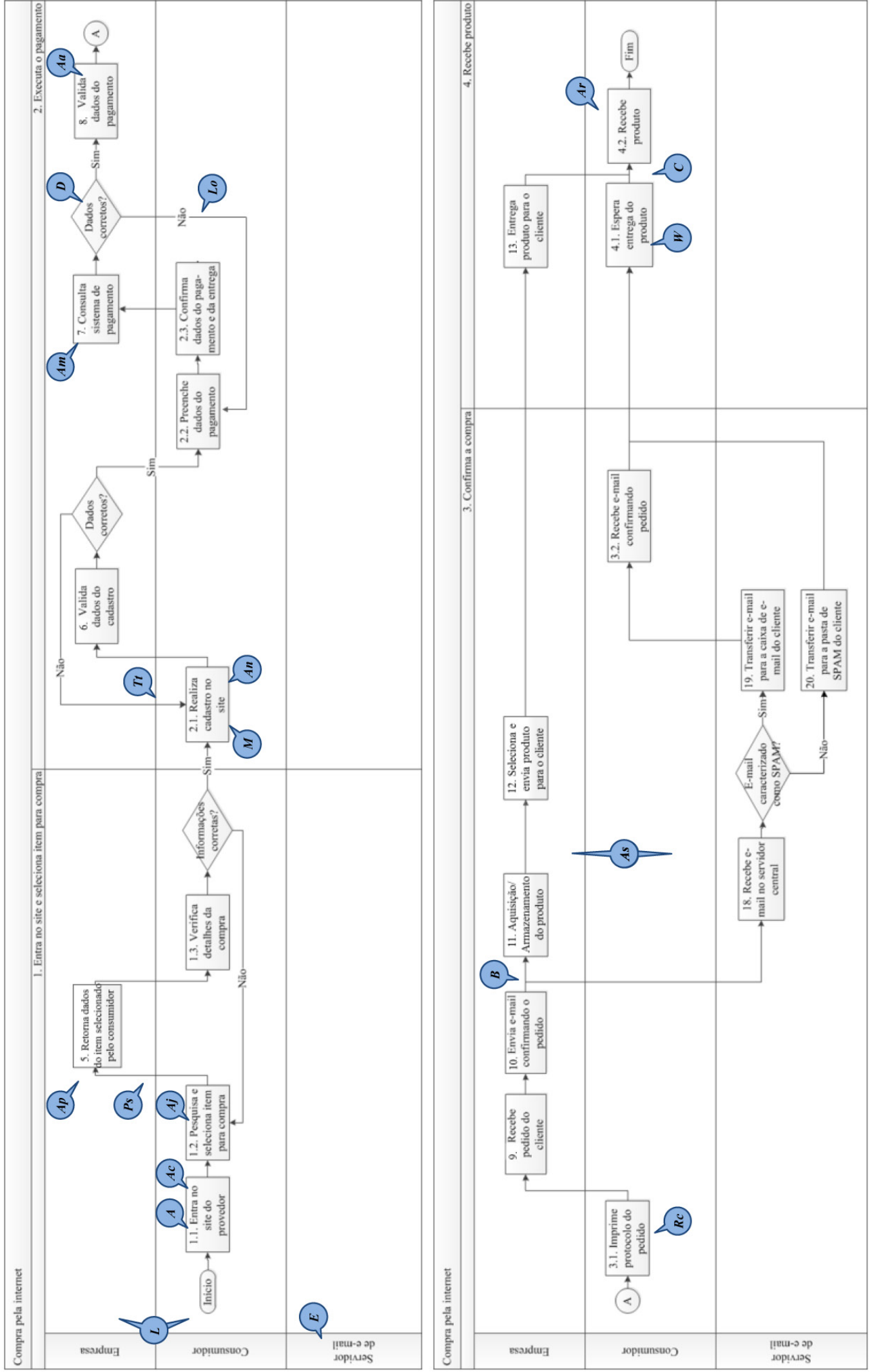

Figura 4. Fluxograma para o processo de compra pela internet. 


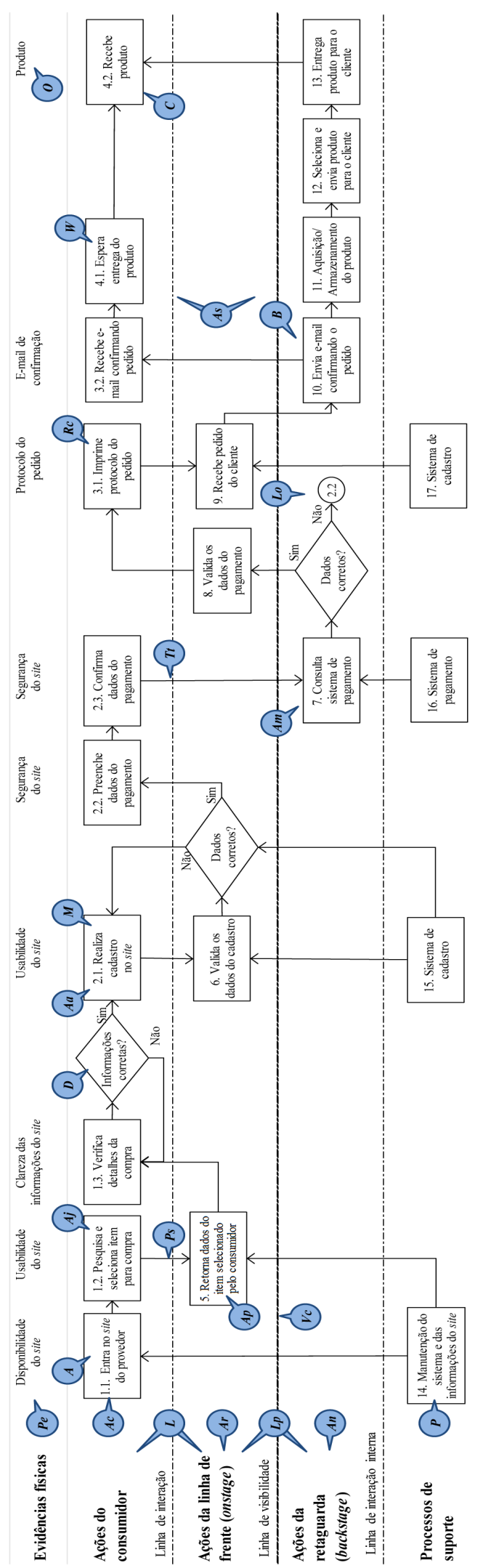

Figura 5. Mapa de Blueprint do processo de compra pela internet. 
"Ações do Consumidor" e as atividades realizadas pela organização provedora do serviço são registradas nas demais raias. Como se pode observar, esta ferramenta permite um alto nível de detalhamento das atividades executadas pela provedora ao separar suas atividades em atividades de linha de frente, retaguarda e processos de suporte. No caso do processo em estudo, a interação entre empresa e consumidor ocorre via site e, portanto, este é o recurso por meio do qual as atividades de linha de frente são executadas.
0 consumidor interage com o site e sua avaliação do processo de serviço é influenciada pela sua percepção acerca desta interação, com base em critérios como usabilidade, agilidade e segurança do site.

Uma visão com escopo mais amplo foi capturada pela aplicação da abordagem da ferramenta PCN que estimula a consideração das interações do consumidor com outras entidades, procurando superar representações que consideram apenas a ocorrência de interações

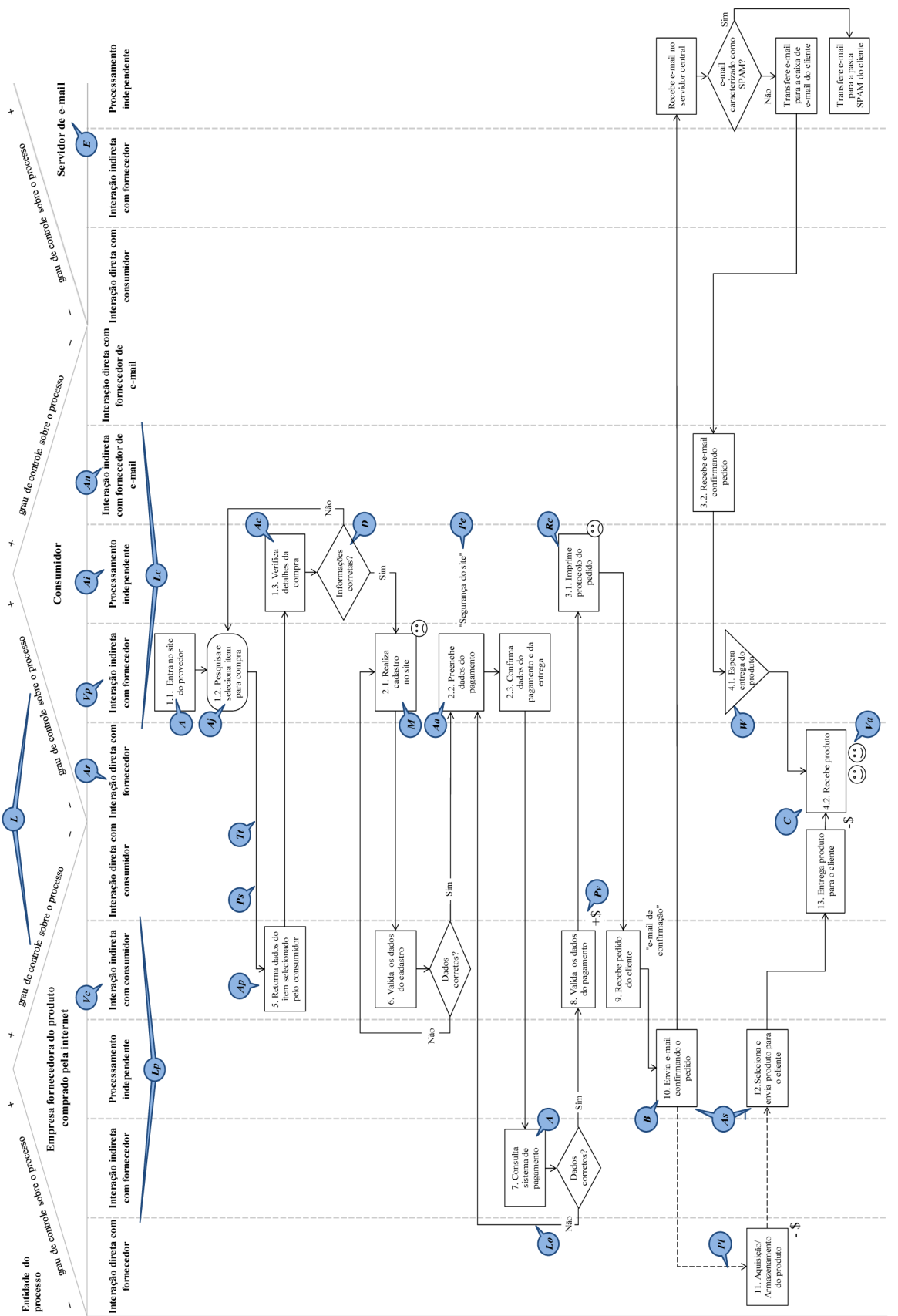

Figura 6. Mapa Process-Chain-Network (PCN) do processo de compra pela internet. 


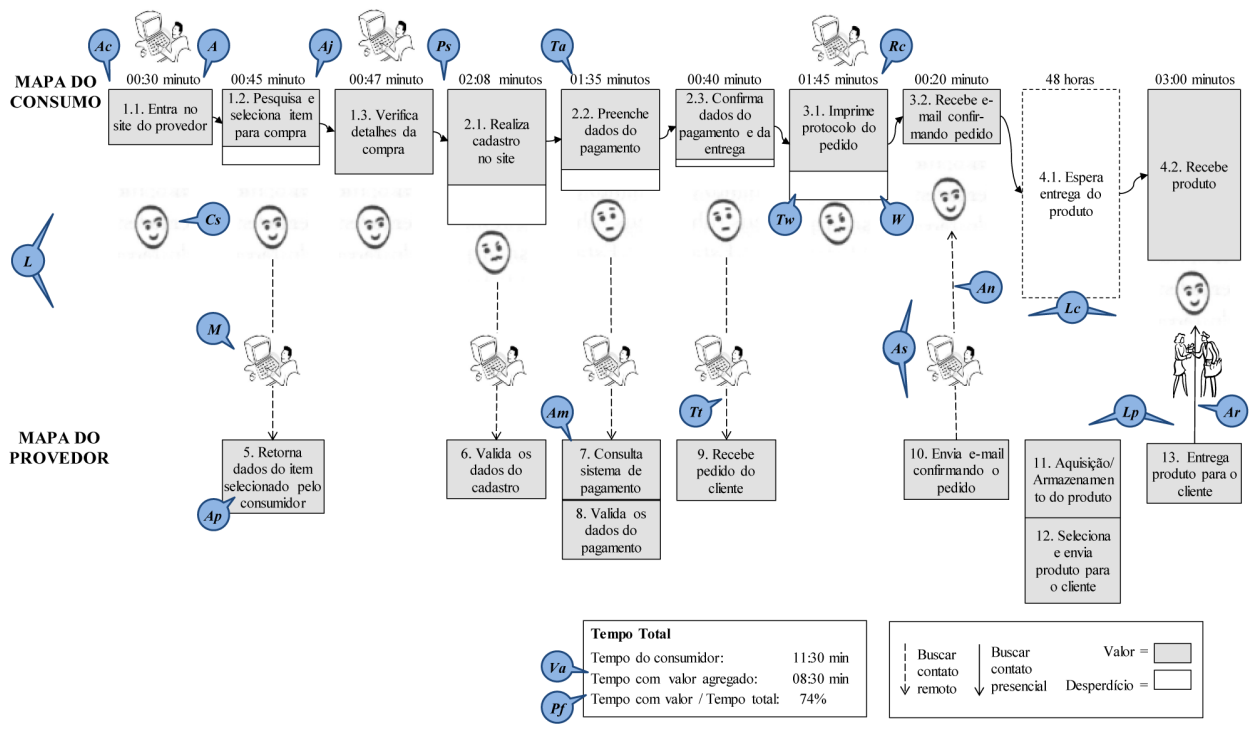

Figura 7. Mapa do Consumo do processo de compra pela internet.

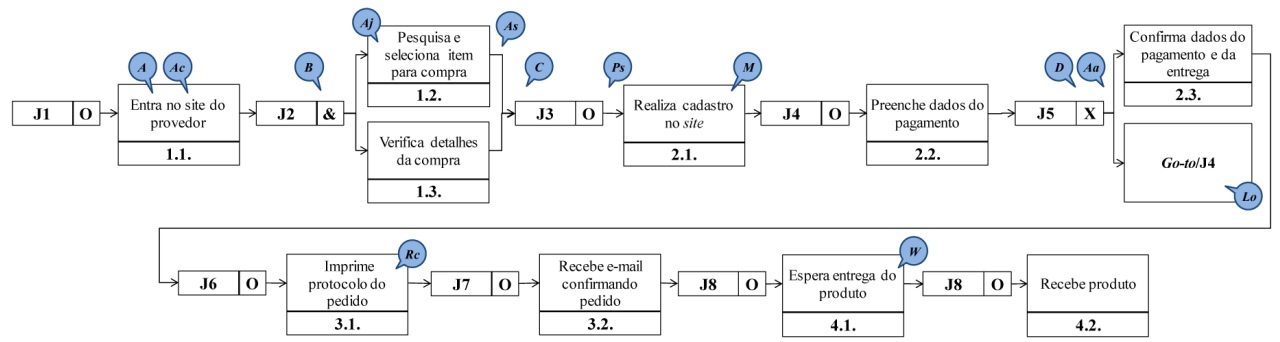

(a) Diagrama

\begin{tabular}{|c|c|}
\hline $\begin{array}{l}\text { Atividade de interação } \mathbf{n}^{\mathbf{0}} \mathbf{2 . 2} \text {. } \\
\text { Nome: Preenche dados do pagamento } \\
\text { Rótulo: Preenche dados do pagamento }\end{array}$ & $\begin{array}{l}\text { Elemento(s) de contato: } \\
\text { Computador } \\
\text { Cartão de crédito } \\
\text { Sistema da empresa }\end{array}$ \\
\hline \multicolumn{2}{|c|}{$\begin{array}{l}\text { Interações entre o(s) elemento(s) e o cliente: } \\
t \rightarrow \text { Cliente seleciona pagamento por cartão de crédito }(2.2 .1) \\
\rightarrow \text { Cliente caminha até a carteira e pega o cartão e volta até o computador }(2.2 .2) \\
\rightarrow \text { Cliente preenche número do cartão, validade, nome do titular e código de segurança } \\
\rightarrow \text { Cliente clica em confirmar pagamento }(2.2 .4) \\
\leftarrow \text { ïl Sistema da empresa captura dados do cartão } \\
\rightarrow \text { Sistema da empresa confirma validade dos dados na base da bandeira } \\
\end{array}$} \\
\hline $\begin{array}{l}\text { Operações do(s) elementos(s): } \\
\text { - Receber dados do cartão } \\
\text { - Confirmar validade dos dados } \\
\text { - Enviar dados para confirmação da entrega }\end{array}$ & $\begin{array}{l}\text { Operações do cliente: } \\
\text { - Selecionar forma de pagamento } \\
\text { - Pegar cartão } \\
\text { - Preencher dados do pagamento } \\
\text { - Confirmar pagamento }\end{array}$ \\
\hline Determinantes da qualidade: & Medidas de desempenho: \\
\hline Rapidez & Tempo médio de resposta do sistema \\
\hline Usabilidade & $\begin{array}{l}\text { \% dos usuários que avaliam a navegação no } \\
\text { site como "fácil" }\end{array}$ \\
\hline Confiabilidade & $\%$ de fraudes nos pagamentos \\
\hline
\end{tabular}

(b) Documento de Elaboração

Figura 8. SERVPRO do processo de compra pela internet. 
diádicas entre o consumidor e o provedor principal do bem ou serviço que busca. Isso é ilustrado pela inclusão do processo de intermediação realizado pelo servidor de e-mail. Além disso, como ilustra o exemplo da Figura 6, esta ferramenta distingue o que ocorre além da região de visibilidade em cada entidade e não som Figura 7. Este mapa apresenta um nível de detalhamento das atividades de processo semelhante ao do mapa de Blueprint e PCN, conforme se pode verificar pela numeração progressiva das atividades representadas. Entretanto, contribui com informações adicionais sobre o processo considerado. Dentre elas, vale destacar como um importante diferencial desta ferramenta, em relação aos mapas gerados com o SIPOC, Blueprint e PCN, a inserção do tempo dedicado pelo consumidor na execução das atividades e sua segregação em parcelas de tempo aproveitado com agregação de valor e de tempo desperdiçado. Assim, o Mapa do Consumo explicita as maiores oportunidades de racionalização do processo em benefício do consumidor. No exemplo de processo considerado, observa-se que o tempo e o esforço dedicados no preenchimento de dados cadastrais excessivos, confirmações excessivas de dados e eventuais esperas ou dificuldades (e.g. na impressão do protocolo), sob a perspectiva do consumidor, constituem desperdícios que não agregam valor e poderiam ser reduzidos ou eliminados.

Uma descrição do processo considerado conforme as convenções do SERVPRO é apresentada pela Figura 8. Nesta representação, o diagrama (item "a") ilustra o fluxo do processo com um nível de detalhamento de atividades semelhante ao adotado no mapa de Blueprint e no Mapa do Consumo, mas indicando de forma mais aderente à realidade de que pode ocorrer um looping entre os pontos $\mathrm{J} 5$ e $\mathrm{J} 4$. Além disso, para atividades específicas, como a 2.2, pode fornecer um documento de elaboração (item "b") com detalhes da dinâmica de interação que ocorre entre o consumidor e recursos da empresa, identificando as microatividades envolvidas, distinguindo-as em ação ou reação e apontando o agente executor delas.

Finalmente, a Carta de Atividades apresentada na Figura 9 desdobra a parte do processo considerado limitada pelas atividades de preenchimento de dados

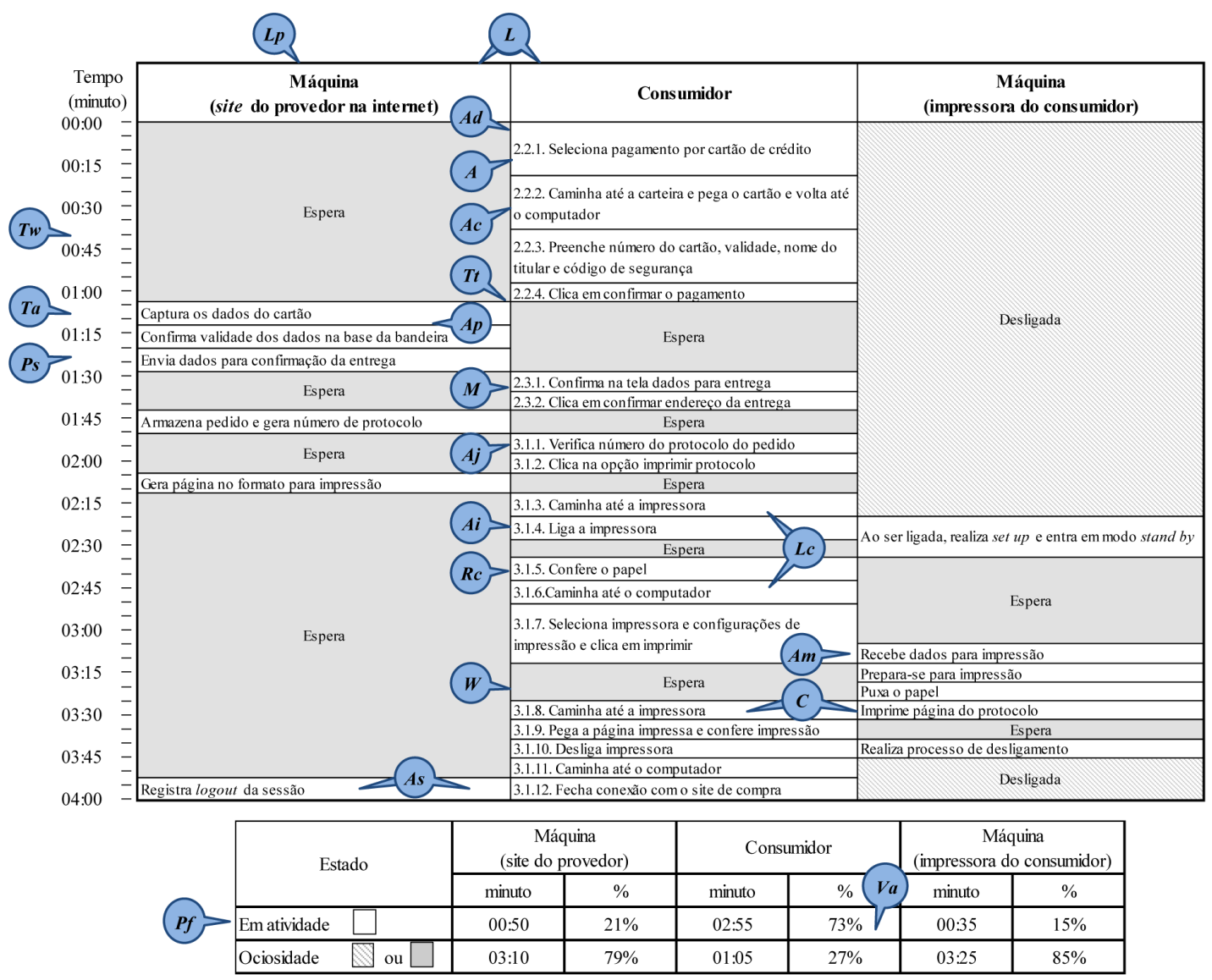

Figura 9. Carta de Atividades para a etapa de pagamento do processo de compra pela internet. 
para pagamento, confirmação dos dados do pagamento e da entrega, e impressão do protocolo do pedido (respectivamente, 2.2, 2.3 e 3.1 nas Figuras 5-8) em uma série de microatividades. Esta forma de mapa exibe o fluxo de atividades seguido pelo consumidor com uma visão mais aprofundada que a adotada nos mapas de Blueprint, PCN, Mapa do Consumo e no diagrama do SERVPRO.

Esta ferramenta identifica as microatividades atribuídas a cada um dos agentes/recursos envolvidos na execução desta etapa do processo e permite uma análise crítica da forma como seus tempos foram gastos. Ao destrinchar as atividades focadas para descrevê-las na Carta de Atividades no nível das microatividades, torna-se possível examinar detalhes como procedimentos específicos que o consumidor tem de seguir num processo e os tempos despendidos na sua execução, pontos de sincronização entre os agentes/recursos envolvidos no processo e ocorrência de esperas. Trata-se, portanto, de uma forma de mapa que aprofunda a análise das atividades sob a responsabilidade do consumidor e força a busca de uma visão minuciosa do aproveitamento de seu tempo.

\section{Comparação entre as ferramentas de mapeamento}

0 conjunto das 7 ferramentas discutidas neste trabalho mostra a diversidade das formas que podem ser adotadas para mapear e evidenciar a participação do consumidor em processos de serviço.

A primeira característica a ser destacada sobre a forma de mapeamento destas ferramentas é o nível de detalhamento adotado na representação das atividades do processo observado. A Figura 10 apresenta os níveis de desdobramento das atividades com que as ferramentas de mapeamento em estudo foram aplicadas na descrição e análise do processo de serviço focado. Enquanto a aplicação do SIPOC sugeriu capturar, inicialmente, uma visão geral da participação do consumidor no processo como uma sequência de 4 macroatividades, as aplicações do Fluxograma, Blueprint, PCN, Mapa do Consumo e diagrama do SERVPRO motivaram o desdobramento destas em 10 atividades mais específicas executadas pelos consumidores. Já a aplicação da Carta de Atividades estimulou a decomposição hierárquica de 3 destas atividades - as numeradas como 2.2, 2.3 e 3.1 - numa sequência de 18 microatividades desempenhadas pelo consumidor. Vale observar que a aplicação do SERVPRO implica também a busca de uma visão mais elaborada das interações que requerem uma análise mais profunda. Assim, no documento de elaboração exemplificado pelo item "b" na Figura 8, o modo de interação da atividade 2.2 é decomposto com um nível de detalhamento semelhante ao da Carta de Atividades. Esta noção de que cada ferramenta deve ser aproveitada adotando-se uma granularidade que lhe é mais adequada para examinar o processo do consumidor é fundamental para se recorrer a elas na condução de um mapeamento e obter uma visão estruturada hierarquicamente.

Para avaliar de forma abrangente o potencial de aplicação das ferramentas de mapeamento aqui consideradas para a representação da participação do consumidor em processos de serviço, a capacidade com que cada ferramenta pode fornecer uma visualização dos 7 principais aspectos do processo mapeado foi avaliada examinando o $G R_{\mathrm{ij}}$ para os 38 tipos de dados apresentados na Tabela 1. A maioria das avaliações de que a ferramenta é capaz de representar o dado considerado no nível pleno ou intermediário foi baseada em evidências como as apontadas pelos balões sobrepostos nas Figuras 3-9. Em 3 avaliações, embora o tipo de dado considerado não estivesse presente na particular figura examinada, como a ferramenta aplicada em si tem a propriedade de poder representá-lo, esta foi avaliada de forma genérica, considerando a possibilidade de aplicação no mapeamento de outros processos. As avaliações assim obtidas são apresentadas na Tabela 3. Conforme se pode observar nesta tabela, as propriedades de representação das ferramentas analisadas variam bastante, revelando as virtudes e limitações de cada uma. Assim, um analista que necessite visualizar a participação do consumidor num processo de serviço

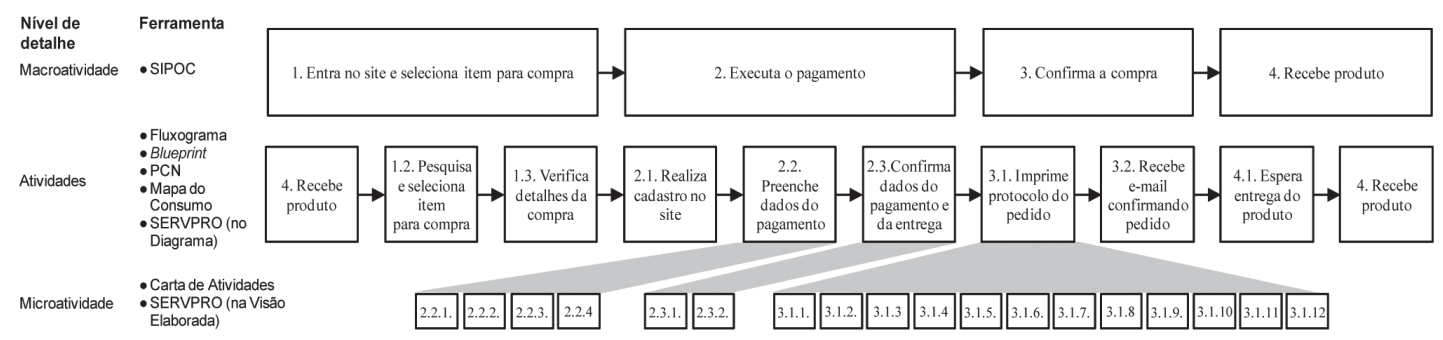

Figura 10. Comparação do nível de detalhamento do fluxo das atividades do consumidor por ferramenta. 
Tabela 3. Avaliação do grau de representação $\left(G R_{i j}\right)$ dos diferentes tipos de dados do processo por ferramenta.

\begin{tabular}{|c|c|c|c|c|c|c|c|c|c|c|}
\hline \multirow{2}{*}{$\begin{array}{l}\text { Aspecto do } \\
\text { processo }\end{array}$} & \multirow[b]{2}{*}{$n_{i}$} & \multirow[b]{2}{*}{ Tipo de dado } & \multirow[b]{2}{*}{ Abreviatura } & \multicolumn{7}{|c|}{ Grau de representação da ferramenta por tipo de dado } \\
\hline & & & & SIPOC & Fluxograma & Blueprint & $\mathrm{PCN}$ & $\begin{array}{l}\text { Mapa do } \\
\text { Consumo }\end{array}$ & $\begin{array}{l}\text { SERV } \\
\text { PRO }\end{array}$ & $\begin{array}{l}\text { Carta de } \\
\text { Atividades }\end{array}$ \\
\hline \multirow{8}{*}{ 1. Ação } & \multirow{8}{*}{8} & Atividade & $A$ & $\bullet$ & $\bullet$ & $\bullet$ & $\bullet$ & $\bullet$ & $\bullet$ & $\bullet$ \\
\hline & & $\begin{array}{l}\text { Atividades síncronas } \\
\text { (simultâneas) ou paralelas }\end{array}$ & As & ○ & - & $\bullet$ & $\bullet$ & $\bullet$ & $\bullet$ & $\bullet$ \\
\hline & & $\begin{array}{l}\text { Atividade alternativa (execução } \\
\text { condicionada a uma decisão) }\end{array}$ & Aa & $\mathrm{O}$ & $\bullet$ & $\bullet$ & $\bullet$ & O & $\bullet$ & $\bigcirc$ \\
\hline & & $\begin{array}{l}\text { Atividade que envolve } \\
\text { julgamento }\end{array}$ & $A j$ & $\odot$ & $\odot$ & $\odot$ & $\bullet$ & $\odot$ & $\odot$ & $\odot$ \\
\hline & & $\begin{array}{l}\text { Visão detalhada no nível de } \\
\text { microatividade }\end{array}$ & $A d$ & O & $\bigcirc$ & $\bigcirc$ & $\bigcirc$ & ○ & $\odot$ & - \\
\hline & & $\begin{array}{l}\text { Processo de suporte } \\
\text { (infraestrutura do provedor) }\end{array}$ & $P$ & O & O & $\bullet$ & $\mathrm{O}$ & O & 0 & O \\
\hline & & $\begin{array}{l}\text { Noção se uma atividade do } \\
\text { consumidor é visível (ou não) } \\
\text { para o provedor }\end{array}$ & $V p$ & O & $\bigcirc$ & O & $\bullet$ & $\bigcirc$ & O & O \\
\hline & & $\begin{array}{l}\text { Noção se uma atividade do } \\
\text { provedor é visível (ou não) para } \\
\text { o consumidor }\end{array}$ & $V c$ & O & ○ & $\bullet$ & $\bullet$ & ○ & 0 & O \\
\hline \multirow{4}{*}{ 2. Motivação } & \multirow{4}{*}{4} & $\begin{array}{l}\text { Saída (output) fornecida por } \\
\text { uma atividade }\end{array}$ & $O$ & $\bullet$ & O & $\odot$ & $\mathrm{O}$ & O & ○ & ○ \\
\hline & & Tomada de decisão & $D$ & ○ & $\bullet$ & $\bullet$ & $\bullet$ & O & $\bullet$ & $\bigcirc$ \\
\hline & & $\begin{array}{l}\text { Indicação de loopíng ou } \\
\text { retrabalho }\end{array}$ & Lo & ○ & $\bullet$ & $\bullet$ & $\bullet$ & ○ & $\bullet$ & O \\
\hline & & $\begin{array}{l}\text { Evidências físicas de uma } \\
\text { atividade (para o consumidor) }\end{array}$ & $\mathrm{Pe}$ & O & O & $\odot$ & $\odot$ & O & 0 & O \\
\hline \multirow{5}{*}{ 3. Agente } & \multirow{5}{*}{5} & $\begin{array}{l}\text { Fornecedor de recurso } \\
\text { (supplier) }\end{array}$ & $S$ & $\bullet$ & O & ○ & ○ & O & ○ & O \\
\hline & & $\begin{array}{l}\text { Indicação de que a atividade é } \\
\text { executada por um provedor }\end{array}$ & $A p$ & O & $\bullet$ & $\bullet$ & $\bullet$ & $\bullet$ & $\odot$ & $\bullet$ \\
\hline & & $\begin{array}{l}\text { Indicação de que a atividade é } \\
\text { executada por uma máquina/ } \\
\text { um sistema }\end{array}$ & $A m$ & ○ & $\odot$ & $\odot$ & $\odot$ & $\odot$ & $\odot$ & $\bullet$ \\
\hline & & $\begin{array}{l}\text { Indicação de que a atividade é } \\
\text { executada pelo consumidor }\end{array}$ & $A c$ & O & $\bullet$ & $\bullet$ & $\bullet$ & $\bullet$ & $\bullet$ & $\bullet$ \\
\hline & & $\begin{array}{l}\text { Interação do consumidor com } \\
\text { outra(s) entidade(s), além do } \\
\text { provedor principal }\end{array}$ & $E$ & O & $\bullet$ & O & $\bullet$ & ○ & 0 & O \\
\hline \multirow{3}{*}{ 4. Local } & \multirow{3}{*}{3} & $\begin{array}{l}\text { Distinção de diferentes locais } \\
\text { onde o provedor executa suas } \\
\text { atividades }\end{array}$ & $L p$ & 0 & $\bullet$ & $\bullet$ & $\bullet$ & $\bullet$ & 0 & $\odot$ \\
\hline & & $\begin{array}{l}\text { Distinção de diferentes locais } \\
\text { onde o consumidor executa } \\
\text { suas atividades }\end{array}$ & $L c$ & O & O & O & $\bullet$ & $\bullet$ & O & $\odot$ \\
\hline & & $\begin{array}{l}\text { Local de execução da atividade } \\
\text { (se local do consumidor ou do } \\
\text { provedor) }\end{array}$ & $L$ & $\odot$ & $\bullet$ & $\bullet$ & $\bullet$ & • & • & $\bullet$ \\
\hline \multirow{5}{*}{ 5. Sequência } & \multirow{5}{*}{5} & $\begin{array}{l}\text { Ramificação do fluxo de } \\
\text { atividades (branching) }\end{array}$ & $B$ & O & • & $\bullet$ & $\bullet$ & O & $\bullet$ & O \\
\hline & & $\begin{array}{l}\text { Convergência de fluxos de } \\
\text { atividades }\end{array}$ & C & 0 & $\bullet$ & $\bullet$ & $\bullet$ & O & $\bullet$ & $\odot$ \\
\hline & & $\begin{array}{l}\text { Relação de precedência entre } \\
\text { um par de atividades (forte no } \\
\text { curto prazo) }\end{array}$ & Ps & $\odot$ & $\bullet$ & $\bullet$ & $\bullet$ & $\bullet$ & $\bullet$ & $\bullet$ \\
\hline & & $\begin{array}{l}\text { Relação de precedência entre } \\
\text { um par de atividades (com } \\
\text { maior defasagem) }\end{array}$ & $P l$ & O & O & ○ & $\bullet$ & O & O & 0 \\
\hline & & $\begin{array}{l}\text { Momento de transição em } \\
\text { que o consumidor aciona o } \\
\text { provedor ou vice-versa }\end{array}$ & $T t$ & O & $\bullet$ & - & $\bullet$ & $\bullet$ & ○ & $\odot$ \\
\hline
\end{tabular}


Tabela 3. Continuação...

\begin{tabular}{|c|c|c|c|c|c|c|c|c|c|c|}
\hline \multirow{2}{*}{$\begin{array}{l}\text { Aspecto do } \\
\text { processo }\end{array}$} & \multirow[b]{2}{*}{$n_{i}$} & \multirow[b]{2}{*}{ Tipo de dado } & \multirow[b]{2}{*}{ Abreviatura } & \multicolumn{7}{|c|}{ Grau de representação da ferramenta por tipo de dado } \\
\hline & & & & SIPOC & Fluxograma & Blueprint & PCN & $\begin{array}{l}\text { Mapa do } \\
\text { Consumo }\end{array}$ & $\begin{array}{l}\text { SERV } \\
\text { PRO }\end{array}$ & $\begin{array}{l}\text { Carta de } \\
\text { Atividades }\end{array}$ \\
\hline \multirow{7}{*}{$\begin{array}{l}\text { 6. Modo/ } \\
\text { meio }\end{array}$} & \multirow{7}{*}{7} & $\begin{array}{l}\text { Entrada (input) recebida por } \\
\text { uma atividade }\end{array}$ & 1 & $\bullet$ & O & O & $\bigcirc$ & O & $\odot$ & O \\
\hline & & $\begin{array}{l}\text { Execução de atividade } \\
\text { independentemente de outra } \\
\text { entidade }\end{array}$ & $\mathrm{Ai}$ & ○ & $\bigcirc$ & ○ & - & $\bigcirc$ & $\bigcirc$ & $\odot$ \\
\hline & & $\begin{array}{l}\text { Execução de atividade } \\
\text { interagindo indiretamente com } \\
\text { outra entidade }\end{array}$ & An & $\bigcirc$ & $\odot$ & $\bullet$ & $\bullet$ & - & $\bigcirc$ & ○ \\
\hline & & $\begin{array}{l}\text { Execução de atividade } \\
\text { interagindo diretamente com } \\
\text { outra entidade }\end{array}$ & $\operatorname{Ar}$ & ○ & $\odot$ & • & - & - & $\bigcirc$ & $\odot$ \\
\hline & & $\begin{array}{l}\text { Fornecimento de recurso pelo } \\
\text { consumidor }\end{array}$ & Rc & $\bullet$ & $\odot$ & $\odot$ & $\odot$ & $\odot$ & $\odot$ & $\odot$ \\
\hline & & $\begin{array}{l}\text { Ocorrência de espera para o } \\
\text { consumidor }\end{array}$ & W & 0 & $\odot$ & $\odot$ & $\bullet$ & - & $\odot$ & $\bullet$ \\
\hline & & $\begin{array}{l}\text { Meio de contato entre } \\
\text { consumidor e provedor }\end{array}$ & M & $\bigcirc$ & $\odot$ & $\odot$ & $\odot$ & - & $\odot$ & O \\
\hline \multirow{6}{*}{ 7. Medida } & \multirow{6}{*}{6} & $\begin{array}{l}\text { Duração do tempo de uma } \\
\text { atividade }\end{array}$ & Ta & 0 & 0 & 0 & 0 & $\bullet$ & 0 & - \\
\hline & & $\begin{array}{l}\text { Duração do tempo de espera } \\
\text { (wait) }\end{array}$ & $\mathrm{Tw}$ & ○ & ○ & O & ○ & • & $\bigcirc$ & $\bullet$ \\
\hline & & $\begin{array}{l}\text { Nível do impacto para a } \\
\text { proposta de valor do provedor }\end{array}$ & $\mathrm{Pv}$ & O & O & O & - & - & O & 0 \\
\hline & & $\begin{array}{l}\text { Medidas de desempenho do } \\
\text { processo (performance) }\end{array}$ & $\mathrm{Pf}$ & $\bigcirc$ & $\bigcirc$ & ○ & O & $\bullet$ & $\odot$ & $\bullet$ \\
\hline & & $\begin{array}{l}\text { Nível de agregação de valor na } \\
\text { atividade (para o consumidor) }\end{array}$ & Va & ○ & 0 & O & • & $\bullet$ & 0 & - \\
\hline & & $\begin{array}{l}\text { Nível de satisfação do } \\
\text { consumidor com a atividade }\end{array}$ & Cs & $\bigcirc$ & ○ & O & $\bigcirc$ & - & $\bigcirc$ & O \\
\hline
\end{tabular}

$n_{\mathrm{i}}=$ número de tipos de dados referentes ao i-ésimo aspecto do processo mapeado. Notação do grau de representação: $\bullet$ Dado pode ser representado graficamente;

○ Dado pode ser registrado por descrição textual; $\bigcirc$ Dado não capturado.

Tabela 4. Graus de representação dos principais aspectos de processo $\left(G R F_{\mathrm{i}}\right)$ por ferramenta.

\begin{tabular}{lccccccc}
\hline \multicolumn{1}{c}{ Aspecto do processo } & SIPOC & Fluxograma & Blueprint & PCN & $\begin{array}{c}\text { Mapa do } \\
\text { Consumo }\end{array}$ & $\begin{array}{c}\text { SERV } \\
\text { PRO }\end{array}$ & $\begin{array}{c}\text { Carta de } \\
\text { Atividades }\end{array}$ \\
\hline Ação & 0,19 & 0,44 & 0,69 & 0,75 & 0,31 & 0,50 & 0,44 \\
Motivação & 0,25 & 0,50 & 0,75 & 0,63 & 0,00 & 0,50 & 0,00 \\
Agente & 0,20 & 0,70 & 0,50 & 0,70 & 0,50 & 0,40 & 0,60 \\
Local & 0,17 & 0,67 & 0,67 & 1,00 & 1,00 & 0,33 & 0,67 \\
Sequência & 0,10 & 0,80 & 0,80 & 1,00 & 0,40 & 0,70 & 0,40 \\
Modo/ meio & 0,29 & 0,36 & 0,50 & 0,71 & 0,64 & 0,29 & 0,43 \\
Medida & 0,00 & 0,00 & 0,00 & 0,33 & 1,00 & 0,08 & 0,67 \\
\hline
\end{tabular}

pode ter de adotar uma ou mais ferramentas em função dos objetivos buscados no caso de mapeamento que estiver tratando.

A aplicação do SIPOC é recomendável na fase inicial do mapeamento em que se procura justamente uma noção geral de um processo que o analista conhece somente superficialmente, cujas fronteiras precisam ser demarcadas formalmente esboçando suas grandes etapas. Um elemento que se destaca no mapa gerado com esta ferramenta é o apontamento dos recursos necessários para a realização de cada uma das macroatividades do processo, especialmente aqueles de que o consumidor precisa dispor.

O Fluxograma, na sua versão com raias, além de induzir o desdobramento das macroatividades em atividades mais específicas, possibilita distinguir claramente as atividades executadas pelo consumidor numa raia separada e identificar outra(s) entidade(s), além do provedor principal, que interage $(\mathrm{m})$ com o consumidor.

0 Blueprint, por incluir as atividades processadas pelo provedor separando-as em linha de frente, 

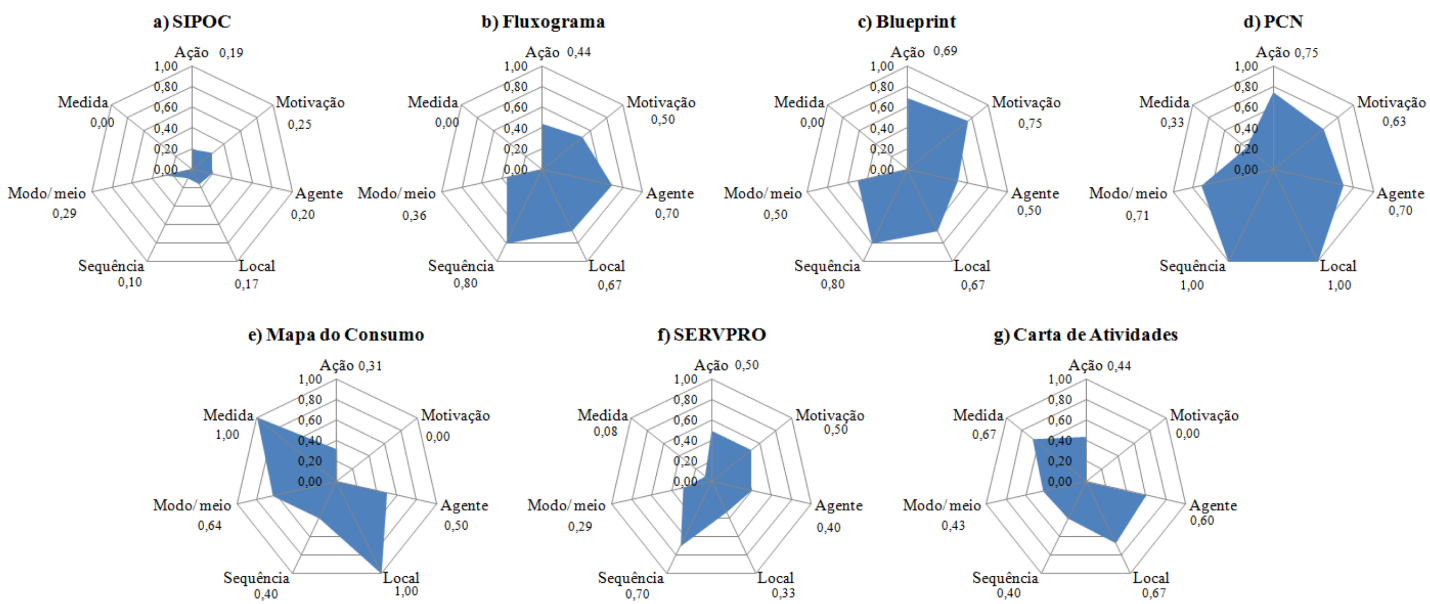

Figura 11. Gráfico radar para o grau de representação $\left(G R F_{i}\right)$ dos 7 aspectos de processo por ferramenta.

Tabela 5. Valor de SMOP por ferramenta.

\begin{tabular}{cccccccc}
\hline indicador & SIPOC & Fluxograma & Blueprint & PCN & $\begin{array}{c}\text { Mapa do } \\
\text { Consumo }\end{array}$ & $\begin{array}{c}\text { SERV } \\
\text { PRO }\end{array}$ & $\begin{array}{c}\text { Carta de } \\
\text { Atividades }\end{array}$ \\
\hline SMOP & 0,07 & 0,72 & 0,84 & 1,49 & 0,83 & 0,42 & 0,55 \\
ordem & 7 & 4 & 2 & 1 & 3 & 6 & 5 \\
\hline
\end{tabular}

Obs. Valor máximo de SMOP: 2,74.

Tabela 6. Grau de representação de tipos de dados específicos ao consumidor.

\begin{tabular}{lccccccc}
\multicolumn{1}{c}{ Indicador } & SIPOC & Fluxograma & Blueprint & PCN & $\begin{array}{c}\text { Mapa do } \\
\text { Consumo }\end{array}$ & $\begin{array}{c}\text { SERV } \\
\text { PRO }\end{array}$ & $\begin{array}{c}\text { Carta de } \\
\text { Atividades }\end{array}$ \\
\hline $\begin{array}{l}\text { pontuação em dados } \\
\text { tipo C } \\
\begin{array}{l}\text { percentagem da pontuação } \\
\text { máxima } \\
\text { ordem }\end{array}\end{array}$ & 1,5 & 5,5 & 6,0 & 9,5 & 8,5 & 4,0 & 5,5 \\
\hline
\end{tabular}

retaguarda e processos de suporte, possibilita o entendimento de como a participação de seus agentes e sua organização interna interferem na experiência do consumidor, sendo a única ferramenta que identifica os processos de suporte necessários para a concretização do serviço, ainda que estes não sejam ativados no atendimento do particular consumidor que estiver sendo considerado.

A ferramenta do PCN compartilha com o Blueprint a propriedade de proporcionar uma visualização mais abrangente das interações entre o consumidor e o provedor, evidenciando os momentos em que ocorrem os "encontros de serviço" e as atividades da linha de frente da organização que influem na qualidade e resultado do serviço prestado sob a perspectiva do consumidor. O PCN adicionalmente estimula a visão da rede valor que envolve o processo de serviço mapeado, lembrando a importância de identificar outra(s) entidade(s) que, além do provedor principal, interage $(\mathrm{m})$ com o consumidor e estendem a noção introduzida pelo Blueprint de segmentar as atividades do provedor conforme sua natureza às atividades de todas as entidades envolvidas, inclusive as do consumidor. Esta ferramenta possibilita, ainda, capturar graficamente dados como a defasagem nas relações de precedência entre as atividades, o nível de impacto para a proposta de valor do provedor e o nível de agregação de valor para o consumidor.

0 Mapa do Consumo é uma forma de representação que se destaca pela ênfase no aspecto da medição, de modo a facilitar a visualização da duração do tempo das atividades, dos tempos de espera, da agregação de valor e do nível de satisfação nas atividades, especialmente sob o ponto de vista do consumidor.

O SERVPRO contempla uma visão do processo tanto no nível de atividades, em seu diagrama, como no nível de microatividades, no documento de elaboração. Sua forma de diagramar o encadeamento das atividades do consumidor de forma mais minuciosa do que a representação linear e unidirecional (sem pontos de retorno, ramificação ou convergência) que é admitida na aplicação de ferramentas como o SIPOC, Mapa do 
Consumo e Carta de Atividades possibilita indicar se elas são sequenciais, paralelas ou alternativas. Além disso, ao preconizar a análise da interação que ocorre numa atividade específica, decompondo-a em ações e reações executadas pelo consumidor ou pelo provedor do serviço num documento de elaboração como o da Figura 8 (item "b"), o detalhamento alcançado se torna semelhante ao de uma Carta de Atividades.

Esta última ferramenta também indica os tempos gastos pelo consumidor para executar determinadas atividades iterativas no processo de serviço, bem como os tempos em que permanece em espera aguardando o provedor concluir suas atividades. São informações valiosas para racionalização de tarefas delegadas ao consumidor e dimensionamento da capacidade dos recursos alocados pelo provedor.

Na Tabela 4 são indicados os valores de GRF que indicam a capacidade de as ferramentas consideradas representarem cada um dos 7 aspectos de processo em análise, e na Figura 11 é apresentado o gráfico radar que exibe estes valores de forma consolidada para cada ferramenta avaliada.

Dentre as ferramentas analisadas, a ferramenta PCN é a que tem a maior capacidade de representar os seguintes aspectos do processo de serviço: ação, sequência e modo/meio. Esta ferramenta, junto com o Fluxograma, também é a mais capaz de representar o aspecto do agente e, junto com o Mapa do Consumo, é a mais capaz de representar o aspecto do local. Já o Blueprint se mostra mais capaz de representar o aspecto da motivação, e o Mapa do Consumo é aquele que melhor representa aspectos de medida.

Contudo, apesar destes destaques, estas ferramentas também revelam limitações. A ferramenta PCN, mesmo apresentando uma capacidade de representação relativamente elevada para 5 aspectos, é limitada para contemplar aspectos de medida. Já tanto o Fluxograma como o Blueprint não incluem nenhum dado de medida, enquanto o Mapa do Consumo não contempla o aspecto da motivação.

As duas ferramentas mais adequadas para aprofundar a visão do fluxo de atividades no nível micro são o SERVPRO e a Carta de Atividade. 0 primeiro revela boa capacidade de detalhamento do aspecto da sequência, e o segundo, do aspecto de medida. Contudo, atingem tal nível de granularidade à custa de uma redução de escopo do fluxo mapeado e captura de uma menor variedade de tipos de dados acerca do processo. Assim, ambas são adequadas para focar uma pequena parte de todo o processo e desmembrá-la em microatividades, mas em comparação com as demais, não se destacam especificamente na representação de nenhum aspecto.

A ferramenta SIPOC, por fim, por ser uma ferramenta destinada ao levantamento de noções gerais do processo, em comparação com as demais, de forma geral revela menor capacidade de representar o processo mapeado.

Comparando os polígonos das Figura 11a-g, nota-se que o da Figura $11 \mathrm{~d}$ referente ao PCN é o de maior superfície. lsso é confirmado pelo correspondente valor de SMOP dado na Tabela 5, que é o maior dentre os 7, indicando que o PCN é a ferramenta com a maior capacidade informativa para a visualização de processos de serviço em que há participação do consumidor por capturar de forma mais abrangente os diferentes aspectos considerados. Em seguida, observa-se na Figura 11 que os polígonos do Blueprint e do Mapa do Consumo são os de maior área, mas não é possível distinguir qual destes tem maior superfície apenas visualmente. A comparação de seus valores de SMOP na Tabela 5 confirma que a avaliação geral de ambos é muito semelhante e que estas duas ferramentas são as que oferecem maior capacidade informativa após o PCN.

Vale ressalvar que a seleção de uma ferramenta de mapeamento não deve ser baseada somente no SMOP. Mapas com maior riqueza de conteúdo informacional implicam na necessidade de alimentá-los com mais dados e, portanto, sua construção exige um esforço maior de observação e medição do processo mapeado. Por esse motivo, é essencial definir claramente que aspecto(s) de processo se pretende capturar com maior atenção para direcionar a seleção da ferramenta mais indicada para o caso, considerando os pontos fortes e fracos de cada ferramenta apresentados na Tabela 4. O PCN pode ter o maior SMOP, mas, por exemplo, para contemplar a motivação do processo, o Blueprint revela propriedades superiores.

Complementarmente, também foi analisada a capacidade de cada ferramenta capturar e representar os tipos de dados que são mais específicos à participação e perspectiva do consumidor, que como indica a Tabela 1 são em 12 no total. A Tabela 6 apresenta a pontuação acumulada nestes tipos de dados e sua conversão em percentagem da pontuação máxima atingível (12). Por esse indicador, obtém-se uma avaliação geral semelhante à baseada no SMOP: o PCN, com a melhor avaliação, junto com o Mapa do Consumo e Blueprint, despontam como ferramentas com maior capacidade de retratar a experiência e percepção do consumidor no processo mapeado. Comparando especificamente o Blueprint e o Mapa do Consumo, que atingiram valores de SMOP muito próximos, nota-se que embora o primeiro seja mais minucioso na descrição do fluxo do provedor, em termos desse indicador que é mais específico ao fluxo do consumidor, o Mapa do Consumo é superior. 


\section{Conclusão}

Tradicionalmente, as ferramentas de mapeamento abordadas pela literatura têm sido adotadas pelas empresas para projetar ou descrever preponderantemente o fluxo das atividades desempenhadas pelos recursos que elas alocam na produção de bens ou serviços. Não obstante o potencial de aplicação das ferramentas de mapeamento transcenda o âmbito dos processos organizacionais, é paradoxal que num contexto de acirramento da concorrência e de elevação dos padrões de consumo, a visualização das atividades desempenhadas pelos consumidores em processos que envolvem interação com as empresas provedoras de serviço continue negligenciada. Mais especificamente, o esforço de captura da experiência do consumidor mereceria receber maior atenção no setor de serviços onde se observa uma tendência de envolvimento mais acentuado dos consumidores em processos de produção de serviço no papel de coprodutores. A baixa disseminação de conhecimentos sobre ferramentas e métodos para orientar a prática do mapeamento das atividades desempenhadas pelos consumidores em interações de serviço também não tem favorecido o investimento de esforços nesta direção.

Diante disso, com base numa pesquisa da literatura sobre mapeamento de processos, este estudo identificou 7 ferramentas que podem servir para estimular a captura da experiência do consumidor no projeto e gestão de serviços, quais sejam, SIPOC, Fluxograma, Blueprint, PCN, Mapa do Consumo, SERVPRO e Carta de Atividades, e desenvolveu exemplos ilustrativos de aplicação destas na descrição e análise de um processo cuja execução depende bastante da participação do consumidor.

A aplicação dessas ferramentas possibilitou gerar mapas bastante representativos do fluxo das atividades desempenhadas pelos consumidores. A análise dos dados capturados por cada ferramenta, sua exemplificação nos materiais obtidos empiricamente e a análise comparativa das ferramentas por meio dos aspectos ação, motivação, agente, local, sequência, modo/meio e medida, permitiu evidenciar as características singulares

Tabela 7. Ferramenta com maior capacidade para representar cada aspecto de processo.

\begin{tabular}{ll}
\hline \multicolumn{1}{c}{ Aspecto } & \multicolumn{1}{c}{ Ferramenta(s) } \\
\hline Ação & PCN \\
Motivação & Blueprint \\
Agente & Fluxograma e PCN \\
Local & PCN e Mapa do Consumo \\
Sequência & PCN \\
Modo/meio & PCN \\
Medida & Mapa do Consumo
\end{tabular}

dos mapas gerados com cada ferramenta, e mostrar como a sua aplicação pode contribuir na busca de um melhor entendimento do fluxo das atividades em processos de serviço em que há participação do consumidor 0 conjunto desses materiais revela que as ferramentas estudadas possuem capacidades informativas diferentes. A Tabela 7 enumera as ferramentas que possuem maior capacidade informativa para cada um dos aspectos de processo considerados.

Em relação aos procedimentos metodológicos, a utilização de gráficos radares e a adoção do indicador SMOP contribuiu para sistematizar a avaliação comparativa da capacidade informativa das ferramentas consideradas.

A adoção de ferramentas de mapeamento sob uma perspectiva mais ampla, considerando todos os agentes envolvidos no processo de consumo, não se restringindo ao levantamento das atividades desempenhadas pelos provedores, é crucial para identificar oportunidades de melhoria no atendimento do consumidor e oferecer-lhe uma melhor proposta de valor. Este artigo aborda este tema de forma exploratória, limitando a pesquisa à avaliação das ferramentas SIPOC, Fluxograma, Blueprint, PCN, Mapa do Consumo, SERVPRO e Carta de Atividades, e focando suas aplicações em um processo de compra pela internet. Novas pesquisas nesse campo do conhecimento, que tratem da construção de mapas que possibilitem a visualização da experiência dos consumidores nos processos de serviço se fazem necessárias, de maneira a: ampliar o leque de ferramentas que podem ser aplicadas com este propósito; desenvolver estudos empíricos que contemplem outros tipos de serviço, além dos serviços "faça você mesmo"; e focar métodos de medição de variáveis como esforço e satisfação do consumidor.

\section{Referências}

Barnes, R. M. (1977). Estudo de movimentos e tempos. São Paulo: Edgard Blücher.

Ben-Shabat, H., Moriarty, M., \& Nilforoushan, P. (2013). Online retail is front and center in the quest for growth: the 2013 global retail E-Commerce index. Recuperado em 11 de fevereiro de 2014, de http://www.atkearney.com/ consumer-products-retail/e-commerce-index.

Berry, L. L., Zeithaml, V. A., \& Parasuraman, A. (1985). Quality counts in services, too. Business Horizons, 28(3), 44-52. http://dx.doi.org/10.1016/0007-6813(85)90008-4.

Biazzo, S. (2000). Approaches to business process analysis: a review. Business Process Management Journal, 6(2), 99-112. http://dx.doi.org/10.1108/14637150010321277.

Bitner, M. J., Ostrom, A. L., \& Morgan, F. N. (2008). Service Blueprinting: a practical technique for service innovation. California Management Review, 50(3), 66-95. http://dx.doi. org/10.2307/41166446. 
Corrêa, H. L., \& Corrêa, C. A. (2004). Administração de produção e operações: manufatura e serviços: uma abordagem estratégica. São Paulo: Atlas.

Damelio, R. (2011). The basics of process mapping (2. ed.). Boca Raton: CRC Press. 65 p.

Daychoum, M. (2007). 40 ferramentas e técnicas de gerenciamento. Rio de Janeiro: Brasport.

Etgar, M. (2008). A descriptive model of the consumer coproduction process. Journal of the Academy of Marketing Science, 36(1), 97-108. http://dx.doi.org/10.1007/s11747007-0061-1.

Fitzsimmons, J. A., \& Fitzsimmons, M. J. (2005). Administração de serviços: operações, estratégia e tecnologia de informação (4. ed.). São Paulo: The Bookman. 537 p.

Fliess, S., \& Becker, U. (2006). Supplier integration: controlling of co-development processes. Industrial Marketing Management, 35(1), 28-44. http://dx.doi.org/10.1016/j. indmarman.2005.07.004.

George, M. L. (2003). Lean Six Sigma for Service: how to use lean speed and six sigma quality to improve services and transactions. New York: McGraw-Hill.

Gil, A. C. (1999). Métodos e técnicas de pesquisa social (5. ed.). São Paulo: Atlas.

Grönroos, C. (1998). Marketing services: the case of a missing product. Journal of Business and Industrial Marketing, 13(4/5), 322-338. http://dx.doi.org/10.1108/08858629810226645.

Gummesson, E. (2008). Extending the service-dominant logic: from customer centricity to balanced centricity. Journal of the Academy of Marketing Science, 36(1), 15-17. http:// dx.doi.org/10.1007/s11747-007-0065-x.

Jacka, J. M., \& Keller, P. J. (2009). Business process mapping: Improving customer satisfaction. New York: Wiley.

Johnston, R., \& Clark, G. (2002). Administração de operações de serviço. São Paulo: Atlas. 562 p.

Kanawaty, G. (Ed.). (1992). Introduction to work study (4. ed). Geneva: International Labour Office.

Koning, H., Does, R. J. M. M., \& Bisgaard, S. (2008). Lean Six Sigma in financial services. International Journal of Six Sigma and Competitive Advantage, 4(1), 1-17. http:// dx.doi.org/10.1504/1JSSCA.2008.018417.

Krajewski, L. J., Ritzman, L. P., \& Malhotra, M. K. (2009). Administração de produção e operações (8. ed.). São Paulo: Pearson.

Kumar, S., \& Steinebach, M. (2008). Eliminating US hospital medical errors. International Journal of Health Care Quality Assurance, 21(5), 444-471. http://dx.doi. org/10.1108/09526860810890431. PMid:18785345.

Kumar, S., Hudson, B., \& Lowry, J. (2010). Consumer purchase process improvements in e-tailing operations: a case study. International Journal of Productivity and Performance Management, 59(4), 388-403. http://dx.doi. org/10.1108/17410401011038928.

Kumar, S., Strandlund, E., \& Thomas, D. (2008). Improved service system design using Six Sigma DMAIC for a major US consumer electronics and appliance retailer. International Journal of Retail \& Distribution Management, 36(12), 970-994. http://dx.doi.org/10.1108/09590550810919388.

Lee, Q., \& Snyder, B. (2006). The Strategos guide to value stream and process mapping. Bellingham: Enna.
Lovelock, C. H., \& Young, R. F. (1979). Look to consumers to increase productivity. Harvard Business Review, 57(3), 168-178.

Madison, D. J. (2005). Process mapping, process improvement, and process management: a practical guide to enhancing work and information flow. Chico: Paton Professional.

Martin, J. C., \& Román, C. (2006). A benchmarking analysis of spanish commercial airports: a comparison between SMOP and DEA ranking methods. Networks and Spatial Economics, 6(2), 111-134. http://dx.doi.org/10.1007/ s11067-006-7696-1.

Mclean-Conner, P. (2006). Customer service: utility style: proven strategies for improving customer service and reducing customer care costs. Tulsa: Penn Well.

Mills, P. K., \& Morris, J. H. (1986). Clients as "partial” employees of service organizations: Role development in client participation. Academy of Management Review, 11(4), 726-735. http://dx.doi.org/10.5465/AMR.1986.4283916.

Mohan, G. \& Sinciya, P. 0. (2013). Real time healthcare system for patients with chronic diseases in home and hospital environments. International Journal of Science, Engineering and Technology Research, 2(4), 931-936.

Nakatsu, R. T. (2010). Diagrammatic reasoning in Al. New Jersey: John Wiley \& Sons.

Parasuraman, A., Zeithaml, V. A., \& Berry, L. L. (1985). A conceptual model of service quality and its implications for future research. Journal of Marketing, 49(4), 41-50. http://dx.doi.org/10.2307/1251430.

Rasmusson, D. (2006). The SIPOC picture book: a visual guide to the SIPOC/DMAIC relationship. Madison: Oriel Incorporated. $19 \mathrm{p}$.

Ravald, A., \& Grönroos, C. (1996). The value concept and relationship marketing. European Journal of Marketing, 30(2), 19-30. http://dx.doi.org/10.1108/03090569610106626.

Sampson, S. E. (2012). Visualizing service operations. Journal of Service Research, 15(2), 182-198. http://dx.doi. org/10.1177/1094670511435541.

Santos, L. C., \& Varvakis, G. (2002). SERVPRO: uma técnica para a gestão de operações de serviços. Revista Produção, 12(1), 34-45.

Schütz, H., Speckesser, S., \& Schmid, G. (1998). Benchmarking labour market performance and labour market policies: theoretical foundation and applications. Discussion Paper FS 1 98-205. Berlin: Wissenschaftszentrum Berlin für Sozialforschung.

Shostack, G. L. (1984). Designing services that deliver. Harvard Business Review, 62(1), 133-139.

Shostack, G. L. (1987). Service positioning through structural change. Journal of Marketing, 51(1), 34-43. http://dx.doi. org/10.2307/1251142.

Smith, G. F. (1998). Quality problem solving. Milwaukee: ASQ Quality Press.

Solomon, M. R., Surprenant, C., Czepiel, J. A., \& Gutman, E. G. (1985). A role theory perspective on dyadic interactions: the service encounter. Journal of Marketing, 49(1), 99-111. http://dx.doi.org/10.2307/1251180.

Stevens, J. D. (1996). Blueprint for measuring project quality. Journal of Management Engineering, 12(2), 34-39. http:// dx.doi.org/10.1061/(ASCE)0742-597X(1996)12:2(34).

Summers, M. R. (1998). Analyzing operations in business: issues, tools, and techniques. Westport: Quorum Books. 
Tiku, S., Azarian, M., \& Pecht, M. (2007). Using a reliability capability maturity model to benchmark electronics companies. International Journal of Quality \& Reliability Management, 24(5), 547-563. http://dx.doi.org/10.1108/02656710710748394.

Torres Junior, N., \& Miyake, D. 1. (2011). A participação do cliente em processos de serviço e as implicações dos possíveis papéis do cliente na criação de valor. Produto \& Produção, 12(1), 91-120.
Tseng, M. M., Qinhai, M., \& Su, C. J. (1999). Mapping customers' service experience for operations improvement. Business Process Management Journal, 5(1), 50-64. http://dx.doi. org/10.1108/14637159910249126.

Womack, J. P., \& Jones, D. T. (2006). Soluções enxutas lean solutions: como empresas e clientes conseguem juntos criar valor e riqueza. Rio de Janeiro: Campus. 298 p.

\section{A comparative study on tools for mapping activities performed by consumers in service processes}

\section{Abstract}

The objective of this article is to explore the potential application of mapping tools to build process maps that bring into view the activities performed by consumers in service processes. The article addresses a set of tools, namely, SIPOC, Flowchart, Blueprint, Process-Chain-Network, Consumption Map, SERVPRO, and Activity Chart, exemplifying their application in the building of maps that offer different visions for an online shopping process undertaking the approach of hierarchical decomposition in the analysis of a consumer's activities flow. These tools are analyzed with regard to their capacity to represent the different aspects of the mapped process, considering characteristics such as the graphic representation form and the focal points, scope, and granularity of the visualization they provide. Finally, a comparative evaluation of the informative capacity of these tools is presented, which highlights the distinct attributes of each one.

\section{Keywords}

Process mapping. Service operations management. Service. Customer. 